Cochrane Database of Systematic Reviews

\title{
Oxygen therapy for cystic fibrosis (Review)
}

Elphick HE, Mallory G

Elphick HE, Mallory G.

Oxygen therapy for cystic fibrosis.

Cochrane Database of Systematic Reviews 2013, Issue 7. Art. No.: CD003884.

DOI: 10.1002/14651858.CD003884.pub4.

www.cochranelibrary.com 
TABLE OF CONTENTS

HEADER 1

ABSTRACT

PLAIN LANGUAGE SUMMARY

BACKGROUND

OBJECTIVES

METHODS

RESULTS

DISCUSSION

AUTHORS' CONCLUSIONS

ACKNOWLEDGEMENTS

REFERENCES

CHARACTERISTICS OF STUDIES

DATA AND ANALYSES

Analysis 1.1. Comparison 1 Oxygen therapy versus control, Outcome 1 Survival.

Analysis 1.2. Comparison 1 Oxygen therapy versus control, Outcome 2 Change in FEV1.

Analysis 1.3. Comparison 1 Oxygen therapy versus control, Outcome 3 Change in FVC.

Analysis 1.4. Comparison 1 Oxygen therapy versus control, Outcome 4 Change in gas exchange during exercise.

Analysis 1.5. Comparison 1 Oxygen therapy versus control, Outcome 5 Change in gas exchange during sleep.

Analysis 1.6. Comparison 1 Oxygen therapy versus control, Outcome 6 Change in PaO2.

Analysis 1.7. Comparison 1 Oxygen therapy versus control, Outcome 7 Change in $\mathrm{PaCO} 2$.

Analysis 1.8. Comparison 1 Oxygen therapy versus control, Outcome 8 Quality of life: regular attendance at school or work. ...

Analysis 1.9. Comparison 1 Oxygen therapy versus control, Outcome 9 Sleep parameters.

Analysis 1.10. Comparison 1 Oxygen therapy versus control, Outcome 10 Exercise parameters after submaximal exercise. .....

Analysis 1.11. Comparison 1 Oxygen therapy versus control, Outcome 11 Exercise parameters during maximal exercise. .........

Analysis 1.12. Comparison 1 Oxygen therapy versus control, Outcome 12 Nutritional status: change in \% ideal body weight for height.

Analysis 1.13. Comparison 1 Oxygen therapy versus control, Outcome 13 Changes in right heart function. ADDITIONAL TABLES

WHAT'S NEW

HISTORY

CONTRIBUTIONS OF AUTHORS

DECLARATIONS OF INTEREST

DIFFERENCES BETWEEN PROTOCOL AND REVIEW

INDEX TERMS 
[Intervention Review]

\section{Oxygen therapy for cystic fibrosis}

Heather E Elphick ${ }^{1}$, George Mallory ${ }^{2}$

${ }^{1}$ Respiratory Unit, Sheffield Children's Hospital, Sheffield, UK. ${ }^{2}$ Texas Children's Hospital, Baylor College of Medicine, Houston, Texas, USA

Contact address: Heather E Elphick, Respiratory Unit, Sheffield Children's Hospital, Western Bank, Sheffield, S10 2TH, UK. H.Elphick@sheffield.ac.uk, Heather.Elphick@sch.nhs.uk.

Editorial group: Cochrane Cystic Fibrosis and Genetic Disorders Group.

Publication status and date: Stable (no update expected for reasons given in 'What's new'), published in Issue 8, 2013.

Citation: Elphick HE, Mallory G. Oxygen therapy for cystic fibrosis. Cochrane Database of Systematic Reviews 2013, Issue 7. Art. No.: CD003884. DOI: 10.1002/14651858.CD003884.pub4.

Copyright @ 2013 The Cochrane Collaboration. Published by John Wiley \& Sons, Ltd.

\section{A B S T R A C T}

\section{Background}

The most serious complications of cystic fibrosis (CF) relate to respiratory insufficiency. Oxygen supplementation therapy has long been a standard of care for individuals with chronic lung diseases associated with hypoxemia. Physicians commonly prescribe oxygen therapy for people with CF when hypoxemia occurs. However, it is unclear if empiric evidence is available to provide indications for this therapy with its financial costs and often profound impact on lifestyle.

\section{Objectives}

To assess whether oxygen therapy improves the longevity or quality of life of individuals with CF.

\section{Search methods}

We searched the Cochrane Cystic Fibrosis and Genetic Disorders Group Trials Register, comprising references identified from comprehensive electronic database searches and handsearches of relevant journals and abstract books of conference proceedings.

Latest search of Group's Trials Register: 15 May 2013.

\section{Selection criteria}

Randomized or quasi-randomized controlled trials comparing oxygen, administered at any concentration, by any route, in people with documented CF for any time period.

\section{Data collection and analysis}

Authors independently assessed the risk of bias for included studies and extracted data.

\section{Main results}

This review includes 11 published studies (172 participants); only one examined long-term oxygen therapy (28 participants). There was no statistically significant improvement in survival, lung, or cardiac health. There was an improvement in regular attendance at school or work in those receiving oxygen therapy at 6 and 12 months. Four studies examined the effect of oxygen supplementation during sleep by polysomnography. Although oxygenation improved, mild hypercapnia was noted. Participants fell asleep quicker and spent a reduced percentage of total sleep time in rapid eye movement sleep, but there were no demonstrable improvements in qualitative sleep parameters. Six studies evaluated oxygen supplementation during exercise. Again, oxygenation improved, but mild hypercapnia resulted. Participants receiving oxygen therapy were able to exercise for a significantly longer duration during exercise. Other exercise parameters were not altered by the use of oxygen. 


\section{Authors' conclusions}

There are no published data to guide the prescription of chronic oxygen supplementation to people with advanced lung disease due to CF. Short-term oxygen therapy during sleep and exercise improves oxygenation but is associated with modest and probably clinically inconsequential hypercapnia. There are improvements in exercise duration, time to fall asleep and regular attendance at school or work. There is a need for larger, well-designed clinical trials to assess the benefits of long-term oxygen therapy in people with CF administered continuously or during exercise or sleep or both. However, we do not expect any new research to be undertaken in this area any time soon and do not plan to update this review again until any new evidence does become available.

\section{PLAIN LANGUAGE SUMMARY}

\section{Additional oxygen in the treatment of cystic fibrosis}

People with cystic fibrosis (CF) suffer from breathing problems. Giving additional oxygen has long been a standard of care for people with chronic lung diseases. It is common for doctors to prescribe this treatment for people with CF when there is not enough oxygen in their blood. We looked for evidence that this treatment improves the length and quality of life for people with CF. We found eleven studies with 172 participants to include in the review. All studies compared low-flow oxygen to room air. Ten of the studies were short-term. Four of the studies looked at giving additional oxygen at night. At night, oxygen levels rose during both rapid eye movement (REM) sleep and non-REM sleep in those people breathing low-flow oxygen. Participants breathing oxygen at night also spent less time in REM sleep and took less time to fall asleep. Six of the studies looked at the effect of extra oxygen on exercise. The levels of oxygen and carbon dioxide in the blood of participants increased during or after exercise when they breathed in low-flow oxygen. People were able to exercise for longer if they breathed in low-flow oxygen. There was more regular attendance at school or work in those receiving long-term oxygen. There is little evidence to support or oppose the long-term use of oxygen therapy in people with advanced CF lung disease. In the short term, treatment has shown some improvement in blood oxygen levels in people with CF during sleep and exercise. This increase in oxygen also came with an increase in carbon dioxide levels, which is probably not clinically important. However, caution needs to be exercised in those with advanced lung disease where this may require further monitoring. There should be research into the effects of long-term oxygen treatment on sleep quality and exercise in people with CF. Unfortunately, we do not expect that any such research will be undertaken any time soon, so we do not plan to update this review again until we find any new trials. 


\section{B A C K G R O U N D}

\section{Description of the condition}

Cystic fibrosis (CF), the most common life-threatening genetic illness in Caucasians, is a chronic disease affecting many secretory organs primarily the lungs and organs involved in gastro-intestinal tract function. With advances in therapy, there has been marked improvement in survival (Fitzsimmons 1996; Frederiksen 1996). However, chronic and recurrent airway-based infection leads to progressive lung damage, bronchiectasis, and fibrosis (Ramsey 1996). These changes ultimately result in chronic hypoxemia (that is, the condition in which the partial pressure of oxygen in the blood of a person breathing room air is less than 60 millimeters of mercury $(\mathrm{mm} \mathrm{Hg}$ ) (equivalent to 8.0 kilopascal $(\mathrm{kPa}))$ or the oxygen saturation of arterial hemoglobin is less than $90 \%$ ) and eventually can lead to pulmonary hypertension (an abnormal persistent elevation of the blood pressure within the pulmonary blood vessels) and cor pulmonale (right sided heart failure). Progressive destruction of lung parenchyma, pulmonary vasculature and pulmonary vasoconstriction secondary to chronic hypoxemia may all play a role in the development of pulmonary hypertension in CF (Fraser 1999).

It is important to acknowledge that there is no universally accepted method of detecting or quantitating hypoxemia in CF or other chronic lung diseases. First, transcutaneous pulse oximetry (reported as the percentage of saturation of arterial hemoglobin by oxygen $\left(\mathrm{SaO}_{2}\right)$ ) has become the most common method in clinical practice and research for measuring oxygenation even though partial pressure of oxygen tension measured on an arterial blood gas is a more accurate measure of oxygenation. Within the literature regarding $\mathrm{CF}$, there have been varied measures of oxygenation including the following: minimum SaO2 (Tepper 1983); a lowered mean $\mathrm{SaO}_{2}$ (Coffey 1991; Milross 2001a); percentage of time spent with $\mathrm{SaO}_{2}$ below 90\% (Frangiolis 2001); or a fall in baseline $\mathrm{SaO}_{2}$ of $\geq 4 \%$ (Narang 2003). This lack of uniformity in definition makes comparison among studies even more difficult. Lastly, gas exchange is a dynamic phenomenon over time when substantial parenchymal lung disease is involved, indicating that the more chronic the study, the more difficult to quantify the adequacy or stability of gas exchange. Nonetheless, oxygen therapy for individuals with hypoxemic lung disease is commonly prescribed and its effects worthy of precise measurement and analysis.

\section{How the intervention might work}

The efficacy of chronic oxygen supplementation in people with chronic obstructive pulmonary disease (COPD) and severe hypoxemia has been well demonstrated. The 'British Medical Research Council Trial' randomized people with COPD and severe hypoxemia to receive either 15 hours of oxygen therapy daily or no oxygen (MRC 1981). Similarly, the 'Nocturnal Oxygen Therapy Trial' in the USA randomized participants with severe COPD and chronic hypoxemia to receive either 12 hours or 24 hours continuous oxygen therapy (NOTTG 1980). In both studies, mortality in the treatment group was significantly lower than that seen in the control or lesser-treated group. Thus, it appears that improvement in survival in individuals with chronic hypoxemia and COPD is related to the use of daily oxygen therapy in people with partial pressure of oxygen in the blood $\left(\mathrm{PaO}_{2}\right)<55 \mathrm{~mm} \mathrm{Hg}(7.3 \mathrm{kPa})$. More recent studies have failed to show a survival benefit in people with
COPD with milder degrees of hypoxemia $\left(\mathrm{PaO}_{2} 56\right.$ to $\left.65 \mathrm{~mm} \mathrm{Hg}\right)(7.4$ to $8.7 \mathrm{kPa}$ ) (Gorecka 1997).

Oxygen therapy is used in people with CF, particularly in those with chronic hypoxemia, to relieve symptoms of dyspnea and fatigue and to retard the development of cor pulmonale (right heart failure) (Schidlow 1993). However, chronic oxygen therapy has its own costs. The estimated cost of chronic oxygen therapy in the USA in 1995 was $\$ 1.8$ billion (Tarpy 1995). Oxygen supplementation may be associated with complications or adverse effects, including suppression of respiratory drive in people with hypercarbia (elevated blood carbon dioxide level), psychological sequelae, and decreased mobility due to the tethering of an individual to a device or tank. It remains unclear whether oxygen therapy alleviates symptoms, alters the natural disease progression or reliably accomplishes any benefit in people with CF. In addition, it is unknown whether oxygen supplementation may be beneficial alone or when used in conjunction with non-invasive ventilation.

An important specific aspect of prescribed oxygen therapy is the context of air travel. Commercial airplanes pressurize cabins to a pressure commensurate with approximately 2500 meters or 8000 feet, which results in modest and clinically insignificant drops in oxygenation in normal individuals. Although there are publications with recommendations regarding the requirement of oxygen therapy in individuals with hypoxemia due to underlying lung disease (Gong 1992), consideration of oxygen therapy during air travel for the individual with CF has not been the subject of study.

\section{Why it is important to do this review}

Pulmonary hypertension and cor pulmonale are believed to be pre-terminal events in the majority of people with CF who die of their respiratory disease. Respiratory failure (the inability of the respiratory system to meet the metabolic demands of the body for oxygen intake and carbon dioxide excretion, leading to hypoxemia and/or elevated partial pressures of carbon dioxide in the blood, usually greater than $50 \mathrm{~mm} \mathrm{Hg}(6.7 \mathrm{kPa}))$ is the usual mechanism of death. Sleep and exercise are the conditions during which individuals with lung disease are particularly at risk for compromised gas exchange. In chronic severe lung disease of all sorts, including CF, hypoventilation (reduced depth of or frequency of breathing, or both, leading to accumulation of carbon dioxide in the blood) and worsened ventilation perfusion mismatching (an imbalance between air flowing into the air sacs of the lung and the blood flow through the lung which leads to abnormal gas exchange) during sleep often leads to worsened gas exchange and resulting in varying degrees of nocturnal hypoxemia and hypercapnia (Milross 2001b).

It is therefore important to determine whether oxygen therapy alleviates symptoms or reliably accomplishes any benefit in people with CF.

\section{OB JECTIVES}

To determine whether the use of oxygen therapy in people with CF is associated with changes in mortality, morbidity, quality of life (including sleep quality) or with any adverse effects. 
Furthermore, we shall search for evidence as to whether the amount of oxygen supplementation, duration (hours per day), and mode of oxygen delivery determine efficacy of clinical effect.

\section{METHODS}

\section{Criteria for considering studies for this review}

\section{Types of studies}

Randomized or quasi-randomized controlled studies.

\section{Types of participants}

Children and adults with CF diagnosed clinically and by sweat or genetic testing including all ages and all degrees of severity.

\section{Types of interventions}

Studies examining therapy with oxygen supplementation in which outcomes are compared with air, for any duration, administered by any means including nasal cannula, face mask, with or without additional ventilatory support such as bilevel positive airway pressure (BiPAP) or continuous positive airway pressure (CPAP).

In studies which involve non-invasive ventilatory support, we will focus predominantly on the impact of oxygen therapy insofar as it can be separated from the actual assistance provided by the mechanical support itself. Studies in which oxygen is administered as therapy for acute respiratory failure or acute hypoxemia will be excluded.

\section{Types of outcome measures}

\section{Primary outcomes}

1. Survival

2. Changes in lung function (including forced expiratory volume at one second $\left(\mathrm{FEV}_{1}\right)$ and forced vital capacity (FVC))

3. Changes in gas exchange (including oxygen saturation as measured by pulse oximetry and arterial blood gases)

\section{Secondary outcomes}

1. Quality of life (as measured by standardized validated questionnaires)

2. Sleep parameters (as measured by polysomnography)

3. Exercise tolerance (as measured by exercise testing)

4. Nutritional status (as assessed by height, weight and body mass index (BMI) and z scores)

5. Changes in pulmonary artery pressure (as measured by transthoracic or trans-esophageal echocardiography)

6. Cost of intervention

7. Adverse effects of therapy

Outcome data were grouped into those measured at one, three, six twelve months and annually thereafter if available. If outcome data were recorded at other time periods then consideration was given to examining these as well.

\section{Search methods for identification of studies}

\section{Electronic searches}

Relevant studies were identified from the Group's Cystic Fibrosis Trials Register using the term: oxygen and ventilatory support.
The Cystic Fibrosis Trials Register is compiled from electronic searches of the Cochrane Central Register of Controlled Trials (Clinical Trials) (updated each new issue of The Cochrane Library), quarterly searches of MEDLINE, a search of EMBASE to 1995 and the prospective handsearching of two journals - Pediatric Pulmonology and the Journal of Cystic Fibrosis. Unpublished work is identified by searching the abstract books of three major cystic fibrosis conferences: the International Cystic Fibrosis Conference; the European Cystic Fibrosis Conference and the North American Cystic Fibrosis Conference. For full details of all searching activities for the register, please see the relevant sections of the Cystic Fibrosis and Genetic Disorders Group Module.

Date of the most recent search of the Group's Cystic Fibrosis Trials Register: 15 May 2013.

\section{Searching other resources}

In addition the reference lists of all publications found by the above methods were searched for additional references.

\section{Data collection and analysis}

\section{Selection of studies}

The authors (GM, DV, JF, HE) independently selected the studies to be included in the review (see Contributions of authors). If disagreement arose on the suitability of a study for inclusion in the review, we reached a consensus by discussion.

\section{Data extraction and management}

The authors obtained complete texts of all published studies and also texts of ambiguous studies based on title and abstract. Any non-English language studies obtained were translated into English. The authors independently reviewed each paper in order to ascertain which were relevant to this analysis. Each author, using standard data acquisition forms, independently extracted data. If disagreement arose on the quality of a study, we reached a consensus by discussion.

\section{Assessment of risk of bias in included studies}

The authors assessed the risk of bias using the six domains described in the Cochrane Handbook for Systematic Reviews of Interventions (generation of sequence, allocation concealment, blinding, incomplete outcome data, selective reporting and other potential sources of bias) (Higgins 2009). They assessed the risk of bias as high, low or unclear.

\section{Measures of treatment effect}

The authors sought data on the number of participants by allocated treated group, irrespective of compliance and whether or not the participant was later thought to be ineligible or otherwise excluded from treatment or follow-up in order to allow an intention-to-treat analysis.

For binary outcome measures, we calculated a pooled estimate of the treatment effect for each outcome across studies and reported the odds ratio (OR) (the odds of an outcome among treatment allocated participants to the corresponding odds among controls) and the $95 \%$ confidence intervals (Cls) as generated from the metaanalyses. 
For continuous outcomes, we recorded either mean change from baseline for each group or mean post-treatment or postintervention values and standard deviation for each group. Then, where appropriate, we calculated a pooled estimate of treatment effect by calculating the mean difference (MD) and reported this with the $95 \% \mathrm{Cls}$ as generated by the meta-analyses. Three studies originally presented data as mean with standard error of the mean (Marcus 1992: McKone 2002; Parsons 1996). We have calculated the standard deviation (SD) from the standard error of the mean (SEM) in order to combine data from these studies in the meta-analyses.

Where studies measured data longitudinally, we based the analysis on the mean change from baseline at either 6 or 12 months or both if available. As only one long-term study was identified, the final time point results were used for the majority of studies which were short term. By treating the time points as independent, the correlation between the time points was assumed to be zero.

\section{Unit of analysis issues}

Ideally when conducting a meta-analysis combining results from cross-over studies, we would have liked to use the methods that are recommended by Elbourne (Elbourne 2002) and Curtin (Curtin 2002). Due to restrictions on the data that were available from the papers, the only method that we were able to use was to treat the cross-over studies as if they were parallel studies. Elbourne says that this approach will produce conservative results as it does not take into account within-patient correlation (Elbourne 2002). Also each participant will appear in both the treatment and control group, so the two groups will not be independent.

\section{Dealing with missing data}

We did not contact any authors for clarification of published results or missing data. In future, if data are missing we would aim to contact the original investigators.

\section{Assessment of heterogeneity}

If for future updates of the review we are able to combine data from a sufficient number of trials (at least four), we will test for heterogeneity between trial results using a standard chisquared test and the $\mathrm{I}^{2}$ statistic (Higgins 2003). This value describes the percentage of total variation across studies that are due to heterogeneity rather than by chance (Higgins 2003). The values of 12 lie between $0 \%$ and $100 \%$, and a simplified categorization of heterogeneity that we plan to use is of low (12 value of $25 \%$ ), moderate ( 12 value of $50 \%$ ), and high ( 12 value of $75 \%$ ) (Higgins 2003).

\section{Assessment of reporting biases}

Publication bias may have been a factor in our review because of the possibility of small unpublished studies which could not be identified in the search. This could be investigated using a funnel plot in the future if more studies are included.

\section{Data synthesis}

We have used a fixed-effect model in our analysis. We planned to use this analysis where there was a low or moderate degree of heterogeneity as defined above. If the $1^{2}$ statistic showed a high degree of heterogeneity we would have analysed the results using a random-effects model.

\section{Subgroup analysis and investigation of heterogeneity}

If we had been able to combine a sufficient number of studies (at least four) and had identified significant heterogeneity (a value of $1^{2}$ over $50 \%$ ), we planned to investigate this by a subgroup analysis according to the degree of disease severity (where $\mathrm{FEV}_{1} 70 \%$ to $80 \%$ will be considered mild; $60 \%$ to $70 \%$ moderate; $50 \%$ to $60 \%$ moderately severe; $34 \%$ to $50 \%$ severe; and less than $34 \%$ very severe (ATS 1991)). This is a post-hoc change since development of the original protocol.

\section{Sensitivity analysis}

If we had been able to combine a sufficient number of studies we would perform a sensitivity analysis to determine the robustness of our results as follows:

1. with and without quasi-randomised studies;

2. with and without studies with unclear allocation concealment.

\section{RE S U L T S}

\section{Description of studies}

Please see the list of abbreviations in the 'Additional tables' section of the review (Table 1 ).

\section{Results of the search}

The original searches identified 15 studies for consideration. These studies examined the use of oxygen therapy in CF either acutely or chronically. Nine studies were included (Gozal 1997; Marcus 1992; McKone 2002; Milross 2001b; Nixon 1990; Parsons 1996; Shah 1997; Spier 1984; Zinman 1989); one study was excluded (Serra 2002); the remaining five studies were listed as 'Awaiting classification'. These five studies were assessed for the review updated in 2008 (Barker 1998 ; Fauroux 2001 ; Fauroux 2004 ; Holland 2003 ; Stewart 2001); of these, four were excluded and the remaining study was eligible for inclusion (Barker 1998). Another study, in a more recent search, has been assessed as eligible for inclusion in the review (Falk 2006). In total, eleven studies with 172 participants are now included in this review (Barker 1998; Falk 2006; Gozal 1997 ; Marcus 1992; McKone 2002; Milross 2001b; Nixon 1990; Parsons 1996; Shah 1997 ; Spier 1984 ; Zinman 1989). Details of the methods, participants, interventions, and outcomes are shown in the Characteristics of included studies section of the review.

The search run in 2010 identified six new studies, all of which were excluded. No new studies were identified for the 2013 update.

\section{Included studies}

\section{Study design}

Only one study was a parallel study (Zinman 1989); the remainder being cross-over in design. With the exception of the Zinman paper, which followed participants for over two years (Zinman 1989), all other studies only examined the efficacy of short-term oxygen (less than two days), either administered during exercise or overnight during sleep.

\section{Participant characteristics}

The diagnosis of CF in all participants in all 11 studies was based on a positive sweat test, typical respiratory or digestive symptoms or a positive family history, or both. 
All 11 studies included participants with moderate to severe obstructive lung disease. Of these, four studies included participants with severe obstructive lung disease with baseline measurements of $\mathrm{FEV}_{1}$ reported as follows: two studies reported the mean (SEM) 31 (3) \% predicted (Parsons 1996) and 62 (5) \% predicted (Shah 1997); one study reported the mean (SD) 29.4 (3.4) $\%$ predicted (Gozal 1997); and the remaining study reported just the mean $41 \%$ predicted (McKone 2002).

In six studies, specific criteria for lung function or gas exchange were included in the methodology (Falk 2006; Marcus 1992; Milross 2001b; Nixon 1990; Spier 1984; Zinman 1989). Two papers based participant selection on blood gas parameters (Marcus 1992; Spier 1984). In one study participants were included if an arterial blood gas on room air showed a $\mathrm{SaO}_{2}$ less than 92\% (Spier 1984). In the Marcus study, participants were included if they had a resting $\mathrm{PaO}_{2}$ less than $70 \mathrm{~mm} \mathrm{Hg}$ (equivalent to $9.33 \mathrm{kPa}$ ), when the arterial carbon dioxide tension $\left(\mathrm{PaCO}_{2}\right)$ was greater than 45 $\mathrm{mm} \mathrm{Hg}(6 \mathrm{kPa})$ on room air, or if they had required multiple hospital admissions (Marcus 1992). Three papers used spirometry as an inclusion criterion (Falk 2006; Milross 2001b; Nixon 1990). Participants were included in the Milross study if $\mathrm{FEV}_{1}$ was less than $65 \%$ predicted (Milross 2001b) and in the Falk study if FEV was between 30 and $70 \%$ predicted (Falk 2006). The Nixon paper enrolled equal numbers of participants with $\mathrm{FEV}_{1}$ under $50 \%$ and over 50\% predicted (Nixon 1990). The Zinman paper enrolled participants based on a combination of spirometry and blood gas measurements, requiring a $\mathrm{FEF}_{25-75}$ less than $25 \%$ predicted or an arterialized capillary blood gas measurement with a $\mathrm{PO}_{2}$ less than $65 \mathrm{~mm} \mathrm{Hg}(8.67 \mathrm{kPa})$ on two occasions, one week apart (Zinman 1989). The remaining five studies did not state inclusion criteria for lung function (Barker 1998; Gozal 1997; McKone 2002; Parsons 1996; Shah 1997).

\section{Interventions}

\section{During sleep}

Four studies reported the effects of nocturnal oxygen supplementation on sleep quality and gas exchange during sleep in the short term (Gozal 1997; Milross 2001b; Parsons 1996; Spier 1984). There were differences in the amount of supplemental oxygen given and in the method of delivery of the oxygen. Two studies compared placebo (room air), low-flow oxygen and oxygen administered via non-invasive positive pressure ventilation (NIPPV) (Gozal 1997; Milross 2001b). One of these compared the effects of room air, low-flow nocturnal oxygen and an average of $2.2 \mathrm{~L} / \mathrm{min}$ oxygen delivered via the NIPPV circuit (Gozal 1997). The second study compared the effects of room air, low-flow oxygen supplementation titrated to keep $\mathrm{SaO}_{2}$ greater than $90 \%$ administered via face mask with low pressure continuous positive airway pressure (CPAP) of 4 to $5 \mathrm{~cm} \mathrm{H}_{2} \mathrm{O}$ and bilevel ventilatory support with or without oxygen to maintain $\mathrm{SaO}_{2}$ greater than 90\% (Milross 2001b). From these two studies, we excluded the data which examined the effects of NIPPV from our analysis (Gozal 1997; Milross 2001b). The remaining two studies compared nocturnal low-flow oxygen and room air (Parsons 1996; Spier 1984). The amount of supplemental oxygen was not stated for one study (Parsons 1996). In the other study, humidified oxygen or compressed air were administered via nasal prongs at $2 \mathrm{~L} / \mathrm{min}$ (Spier 1984).
One study looked at the effects of long-term oxygen therapy in hypoxemic CF participants during sleep (Zinman 1989). Twentyeight children and adults were enrolled in three Canadian centers. Participants were randomized to receive either oxygen supplementation to achieve a $\mathrm{PaO}_{2}$ of $70 \mathrm{~mm} \mathrm{Hg}$ or room air administered from a concentrator type device in the home. Treatment was administered during sleep via facemask or nasal cannula. A limitation of the study was the failure to assess the adequacy of oxygenation during sleep with the prescribed therapy. Participants had the option of changing the route of administration, in which case the flow of oxygen necessary to maintain ${\mathrm{a} \mathrm{PO}_{2}}^{3} 70$ $\mathrm{mm} \mathrm{Hg}$ was recalculated. During hospitalizations, the participant's physician determined oxygen requirements. Adherence to therapy was determined by correlating participant logs with timers on the concentrators (Zinman 1989). The aim of the study was to determine the impact of chronic oxygen therapy in advanced CF lung disease on morbidity and mortality. Outcomes measured included death, measures of pulmonary function, anthropometric measurements, exercise tests and radionuclide angiography to assess right heart function. Structured questionnaires were used to assess cognitive function, memory capacity and the participants' sense of self-esteem. The study design called for outcome variables to be measured at intervals up to 36 months post-enrolment (Zinman 1989).

\section{During exercise}

Six studies looked at the effects of oxygen therapy on exercise; five studies evaluated the effects of short-term oxygen supplementation on exercise tolerance (Barker 1998; Falk 2006; Marcus 1992; McKone 2002; Nixon 1990) and one study examined the ability of oxygen to enhance recovery from exercise and to improve performance of a subsequent bout of exercise (Shah 1997). None of these studies used control groups but instead looked at participants with CF with and without oxygen supplementation.

The six studies used different oxygen concentrations: five used fraction of inspired oxygen $\left(\mathrm{FiO}_{2}\right) 1.00$ (Shah 1997); $\mathrm{FiO}_{2} 0.30$ (Marcus 1992; Nixon 1990); $\mathrm{FiO}_{2} 0.39$ (McKone 2002) and FiO2 0.4 (Barker 1998). The sixth study considered participants at sea level and at Dead Sea level (396 m below sea level) (Falk 2006). The elevated barometric pressure at low altitude was used as a method of increasing the quantity of inspired oxygen and therefore the exact amount of oxygen supplementation can not be quantified (Falk 2006).

Different exercise protocols were used in these six studies. In one study, the participants performed initially to maximal exercise capacity and then underwent two supramaximal $(130 \%$ of the workload calculated during maximal exercise) exercises 10 minutes apart; after one of which they breathed room air and after the other $\mathrm{FiO}_{2}$ of 1.0 (Shah 1997). Two studies used a protocol of two progressive exercise tests in which the participants exercised to exhaustion (Marcus 1992; Nixon 1990). In a further study, individuals exercised at $80 \%$ of maximal workload to exhaustion (McKone 2002). In another study, a graded submaximal test at each of three velocities, followed by a maximal exercise test, followed by a six-minute walk test were performed (Falk 2006). The final study used submaximal cycle ergometry using pseudo-random binary sequences of workload (PRBS) (Barker 1998). 
The participants in each of the six exercise studies were randomized to receive room air during one exercise and oxygen supplementation during the second session. One of these studies split participants into two groups based on whether or not they desaturated during exercise while breathing normal air (Nixon 1990). If their peak $\mathrm{SaO}_{2}$ remained above 90\% during exercise, participants were allocated to the "High Sat" group, but if their peak $\mathrm{SaO}_{2}$ was measured at $90 \%$ or below, they were allocated to the "Low Sat" group (Nixon 1990). It is unclear whether this was an a priori division or was made on retrospective analysis (Nixon 1990). We did not anticipate such a division and this is a post hoc change for this review.

Measured parameters in the five studies looking at short-term oxygen supplementation on exercise tolerance included heart rate, maximal oxygen uptake, maximal carbon dioxide $\left(\mathrm{CO}_{2}\right)$ production, peak minute ventilation and arterial oxyhemoglobin saturation (Barker 1998; Falk 2006; Marcus 1992; McKone 2002; Nixon 1990). The Barker study measured respiratory exchange ratio and spectral analysis of the PRBS data (Barker 1998). In addition, the Falk study measured peak oxygen consumption $\left(\mathrm{VO}_{2} \mathrm{pk}\right)$, ventilatory equivalent $\left(\mathrm{Ve} / \mathrm{VO}_{2}\right)$, ventilatory reserve utilisation (VE/MVV), blood lactate (La) and a rating of overall perceived exertion (Falk 2006). Maximum partial pressure of carbon dioxide exhaled during a tidal breath $\left(\mathrm{PETCO}_{2}\right)$ was measured in two studies (Marcus 1992; McKone 2002) and transcutaneous $\mathrm{PCO}_{2}\left(\mathrm{tPCO}_{2}\right)$ was also measured in two studies (Marcus 1992; Nixon 1990).

\section{Excluded studies}

In total 11 studies have been excluded. One study was excluded immediately from the original search because it involved the use of oxygen only in conjunction with assisted ventilation (Serra 2002). Four studies were excluded because they were comparing the use of oxygen in conjunction with two modes of ventilation (Elkins 2004; Fauroux 2001; Fauroux 2004; Young 2008). Two studies were excluded as they compared chest physiotherapy with or without pressure support (Fauroux 1999; Placidi 2006). Another study was excluded because it was comparing two methods of airway clearance (Holland 2003). The ninth study was excluded because it was comparing compressed air with added nitric oxide (Stewart 2001). The remaining two studies were excluded as they looked at aerosolisation with or without pressure support (Fauroux 2000) and the use of dornase alfa with or without pressure support (Riethmueller 2006).

\section{Risk of bias in included studies}

Methodological information was abstracted from all studies, and assessed for risk of bias independently by the authors (see Contributions of authors).

\section{Allocation}

\section{Randomization}

All studies reported that the order of interventions was randomized, but no study reported the method of randomization used. The risk of bias for randomization for all studies is therefore uncertain.

\section{Concealment of allocation}

No study reports give details of concealment of allocation and so the risk of bias has been graded as uncertain in the tables for each study (Characteristics of included studies).

\section{Blinding}

Due to the nature of the intervention it is difficult to blind participants and physicians to treatment.

\section{Blinding of Participants}

Two studies were judged as not having blinded the participants to the gas mixture administered. One study took place at two locations, one at sea level and one at the Dead Sea; therefore participants could not be blinded (Falk 2006). Another study states that participants were aware of the nature of the intervention on the second and third nights of the study (oxygen or NIPPV) due to the interface used (Gozal 1997). These studies were judged to have a high risk of bias from blinding.

Five studies were judged as having blinded participants to the type of therapy administered and to have a low risk of bias (Marcus 1992; McKone 2002; Shah 1997; Nixon 1990; Zinman 1989).

The other four studies did not discuss the degree of blinding used and were judged as unclear (Barker 1998; Milross 2001b; Parsons 1996; Spier 1984).

\section{Blinding of Clinicians}

Two studies were judged as not having blinded the clinicians to the gas mixture administered, for the same reasons as the participants stated above, and judged to have a high risk of bias (Falk 2006; Gozal 1997). One study did not blind the primary investigator (McKone 2002).

Two studies were judged as having blinded the supervising clinicians to the type of therapy administered (Nixon 1990; Zinman 1989), although this was only the case for the participants at home in one study (Zinman 1989).

The other six studies did not discuss the degree of blinding used and were judged as having an uncertain risk of bias (Barker 1998; Marcus 1992; Milross 2001b; Parsons 1996; Shah 1997; Spier 1984).

\section{Blinding of Outcome Assessors}

All of the studies were judged as having an uncertain risk of bias from the blinding of outcome assessors. In one study it was unclear whether the supervising physician was also the outcome assessor (McKone 2002) and in the remaining 10 studies, blinding of assessors was not discussed (Barker 1998; Falk 2006; Gozal 1997; Marcus 1992; Milross 2001b; Nixon 1990; Parsons 1996; Shah 1997; Spier 1984; Zinman 1989).

\section{Incomplete outcome data}

No study explicitly states that an intention-to-treat analysis was conducted.

No study was judged to have a high risk of bias due to incomplete outcome data reporting.

Seven of the studies were judged to have a low risk of bias due to incomplete outcome data reporting. In three studies, data appear 
to have been analyzed based on all enrolled participants; these studies state that all participants completed all the exercises and therefore were judged to have a low risk of bias (Barker 1998; McKone 2002; Shah 1997). In another study, data were analyzed on all enrolled participants; however, two participants were also analyzed as a separate group due to obstructive sleep apnoea symptoms; this study was also considered to be low risk (Spier 1984). In a fifth study, data from three participants were not analysed as they were unable to complete the exercise tests (Falk 2006). Since a reason was given for non-inclusion, this also was judged as having a low risk of bias. In one further study, six out of eight participants completed the study; two participants were enrolled, but later excluded from the study as they did not tolerate NIPPV (Gozal 1997). As these participants were withdrawn due to the NIPPV treatment rather than the oxygen treatment, this was judged as having a low risk of bias for the purposes of this review. In the final study, the data were analyzed both on an intention-totreat basis and on the 18 participants who completed the study (10 participants dropped out - four from the oxygen group and six from the room air group) (Zinman 1989). Although a rise in $\mathrm{PaCO}_{2}$ greater than $5 \mathrm{~mm} \mathrm{Hg}$ was determined a priori to be grounds to exclude a participant from the study, there were no exclusions for this reason because this eventuality did not occur. The follow-up of all participants with respect to survival data was complete (Zinman 1989).

The remaining studies were judged to have an uncertain risk of bias due to incomplete outcome data reporting. Two studies analyzed data on participants with less than 15\% exclusions (Marcus 1992; Nixon 1990). In one of those studies, all but one participant completed the exercise tests; it is not stated whether the results were analyzed to include this participant (Marcus 1992). In the second of those studies, data from two participants were not analyzed, as they were too young to co-operate sufficiently; it was unclear as to whether these two participants were from the same group and therefore unclear as to whether their withdrawal led to a risk of bias (Nixon 1990). In one study 11 participants underwent full nocturnal polysomnography, but it is not clear if the results reported are from all participants or just the seven who had arterial blood gas measurements taken prior to the first part of the study and after each subsequent part (Parsons 1996). In another study there were incomplete arterial blood gas measurements for four participants and it is unclear if the results reported are for all participants or not (Milross 2001b).

\section{Selective reporting}

All studies were judged as uncertain for selective reporting bias as no study mentioned all outcomes. If parameters were not mentioned they were assumed not to have been measured.

Survival data, changes in lung function, changes in gas exchange, quality of life, Wmax, nutritional status and changes in pulmonary artery pressure were reported in full in one study (Zinman 1989). Changes in lung function, changes in gas exchange and exercise tolerance reported in a further study (Falk 2006). Changes in gas exchange and sleep parameters were reported in full in three studies (Gozal 1997; Parsons 1996; Spier 1984). Changes in gas exchange and exercise tolerance were reported in full in four studies (Marcus 1992; McKone 2002; Nixon 1990; Shah 1997).

Barker reported changes in gas exchange and exercise tolerance but no statement of statistical significance was given (Barker 1998).
Data were reported for gas exchange and sleep parameters by Milross (Milross 2001b). However, upon inspection the data appear skewed and could not be included in meta-analysis. Lung function data were measured by McKone but analysis not reported (McKone 2002). This may have been because results were not significant.

Other than in the Zinman paper, survival was not specifically mentioned but data were present for all patients at the end of the study in each paper and it was assumed therefore that survival was not mentioned because all patients survived.

\section{Other potential sources of bias}

There were no other potential sources of bias identified in any of the studies. These were all graded as uncertain as it is not possible to ascertain for certain whether other biases were present.

\section{Effects of interventions}

Please see the full list of abbreviations in the 'Additional tables' section of the review (Table 1). Only significant results are reported.

\section{Primary outcomes}

\section{Survival}

Long-term oxygen therapy, as defined in the landmark studies in the 1980s, has never been studied in CF. The long-term use of nocturnal oxygen supplementation had no discernible effect on mortality (Zinman 1989). Based on intention-to-treat, Zinman reported 4 out of 14 (29\%) deaths in the oxygen group and 4 out of $14(29 \%)$ deaths in the placebo group (Zinman 1989). Of those who completed the study, there were 2 out of 10 deaths (20\%) in the oxygen group as compared to 0 out of $8(0 \%)$ deaths in the air group. Two participants in each group were withdrawn in order to receive oxygen therapy for declining clinical status. When these data are entered into the graphs they give a non-significant result (Analysis 1.1).

\section{Changes in lung function}

Only one study reported on changes in lung function; this was the study which examined the effects of long-term nocturnal oxygen therapy (Zinman 1989). There was no significant change in $\mathrm{FEV}_{1}$ after either six months or after 12 months (Analysis 1.2). Furthermore, there was no significant difference in FVC after six months or after 12 months (Analysis 1.3).

\section{Changes in gas exchange}

Eight studies reported changes in gas exchange in people with CF with and without supplementary oxygen therapy, of which seven reported short-term changes after exercise (Falk 2006; Marcus 1992; McKone 2002; Nixon 1990; Shah 1997) or sleep (Gozal 1997; Parsons 1996; Spier 1984). The eighth study reported changes in $\mathrm{PO}_{2}$ and $\mathrm{PCO}_{2}$ on blood gases after 12 months of nocturnal oxygen therapy (Zinman 1989).

Data from the Marcus, McKone and Parsons studies were originally presented as mean (standard error of the mean). We therefore calculated the standard deviation using the formula $\mathrm{SD}=\mathrm{SE}$ $x$ square root of $n$, to enable data to be used in the metaanalysis (Marcus 1992; McKone 2002; Parsons 1996). Data were only entered for the "High Sats" group in the Nixon study unless stated 
otherwise, as the "High Sats" and "Low Sats" data could not be combined (Nixon 1990).

\section{a. Changes in gas exchange during exercise}

\section{i. Gas exchange at the end of submaximal exercise}

Three studies reported absolute values for $\mathrm{SaO}_{2}$ post exercise (McKone 2002; Nixon 1990; Falk 2006). There was a significant improvement in $\mathrm{SaO}_{2}$ levels with administration of supplementary oxygen after submaximal exercise, MD 2.11 (95\% Cl 1.54 to 2.68$)$ ( $P$ $<0.00001)$. There was no significant difference in post-exercise endtidal $\mathrm{CO}_{2}$ tension $(\mathrm{PET} \mathrm{CO} 2$ ) (Analysis 1.4).

\section{ii. Gas exchange during maximal exercise}

Four studies reported measures of gas exchange during maximal exercise (Falk 2006; Marcus 1992; Nixon 1990; Shah 1997) (Analysis 1.4). The Marcus study reported changes in $\mathrm{SaO}_{2}, \mathrm{PET} \mathrm{CO}_{2}$ and transcutaneous $\mathrm{CO}_{2}$ tension $\left(\mathrm{tPCO}_{2}\right.$ ) during maximal (peak) exercise (Marcus 1992). Nixon reported pooled changes in PET $\mathrm{CO}_{2}$ for the "High Sats" and "Low Sats" groups (Nixon 1990). Supplementary oxygen administration during maximal exercise significantly improved all three parameters: $\mathrm{SaO}_{2}, \mathrm{MD} 7.00(95 \% \mathrm{Cl}$ 2.61 to 11.39$)(\mathrm{P}=0.002$ ) (Marcus 1992); $\mathrm{PET} \mathrm{CO} 2, \mathrm{MD} 3.71(95 \%$ $\mathrm{Cl} 1.28$ to 6.14) ( $\mathrm{P}=0.003)$ (Marcus 1992; Nixon 1990); and $\mathrm{PCOO}_{2}$, MD 4.00 (95\% Cl 1.23 to 6.77) ( $P=0.005)$ (Marcus 1992). Three studies reported absolute $\mathrm{SaO}_{2}$ figures during maximal exercise and the use of supplementary oxygen during maximal exercise also significantly improved $\mathrm{SaO}_{2}, \mathrm{MD} 2.01(95 \% \mathrm{Cl} 1.16$ to 2.85$)(\mathrm{P}<$ 0.00001) (Falk 2006; Nixon 1990; Shah 1997). Additionally, Nixon reports the absolute values of $\mathrm{PETCO}_{2}$ for the "Low Sat" and "High Sat" groups individually. During peak exercise in room air, $\mathrm{PETCO}_{2}$ was significantly higher in the "Low Sat" group compared to the "High Sat" group, mean (SD) 43.00 (8.00) compared to 34.00 (3.00) $\mathrm{mm} \mathrm{Hg}(\mathrm{P}<0.005)$ (Nixon 1990).

\section{b. Changes in gas exchange during sleep}

Three studies examined changes in $\mathrm{SaO}_{2}$ and $\mathrm{CO}_{2}$ levels during sleep (Gozal 1997; Parsons 1996; Spier 1984). Values were reported for rapid eye movement (REM) sleep, non-REM sleep and total sleep. Since different units were used for recording transcutaneous $\mathrm{CO}_{2}$ tension ( $\mathrm{PCO}_{2}$ in $\mathrm{kPa}$ (Gozal 1997) and $\mathrm{TcPCO}_{2}$ in $\mathrm{mm} \mathrm{Hg}$ (Spier 1984; Parsons 1996)) results could not be combined for the metaanalysis (Analysis 1.5).

\section{i. Gas exchange during REM sleep}

There was a significant improvement in $\mathrm{SaO}_{2}$ during REM sleep with supplementary oxygen, MD $7.54(95 \% \mathrm{Cl} 4.31$ to 10.77$)(\mathrm{P}<0.00001)$ (Gozal 1997; Parsons 1996). The transcutaneous $\mathrm{CO}_{2}$ tension (in $\mathrm{kPa}$ ) was found to be significantly higher with oxygen therapy in the Gozal study, MD 1.00 (95\% Cl 0.15 to 1.85 ) ( $P=0.02$ ) (Gozal 1997), but no significant difference was seen in the Spier study which recorded values in $\mathrm{mm} \mathrm{Hg}$ (Spier 1984).

\section{ii. Gas exchange during non-REM sleep}

A significant improvement in $\mathrm{SaO}_{2}$ readings was also seen in nonREM sleep with supplementary oxygen, MD 6.00 (95\% Cl 1.92 to 10.08) $(\mathrm{P}=0.004)$ (Gozal 1997). Transcutaneous $\mathrm{CO}_{2}$ levels were not significantly different in the room air versus oxygen therapy groups (Gozal 1997) and (Spier 1984).

\section{iii. Gas exchange during total sleep}

In the original paper, Parsons reported a significant increase in $\mathrm{tPCO}_{2}$ in participants treated with oxygen during sleep (Parsons 1996). Results were presented as mean (SEM); we calculated the SDs in order to enter the data into a meta-analysis. Entering the maximum value for $\mathrm{tPCO}_{2}$ into the data tables did not give a significant result for this outcome. Parsons also reported the change in $\mathrm{PaCO}_{2}$. The increase in $\mathrm{PaCO}_{2}$ was reported as significant in the oxygen night only and changed from a baseline measurement of mean (SEM) 44.00 (1.00) $\mathrm{mm} \mathrm{Hg}$ to 49.00 (3.00) $\mathrm{mm} \mathrm{Hg}(P=0.04)$ (Parsons 1996). No data were presented for the room air night and so we were unable to enter these results into the meta-analysis.

\section{c. Changes in gas exchange after 12 months}

Zinman measured changes in arterial blood gases $\left(\mathrm{PaO}_{2}\right.$ and $\left.\mathrm{PCO}_{2}\right)$ after 12 months therapy (Zinman 1989). Oxygen flow was titrated to achieve a defined improvement in oxygenation and $\mathrm{PaO}_{2}$ was measured at 12 months on that flow. There was no significant change in $\mathrm{PaO}_{2}$ (Analysis 1.6) or $\mathrm{PaCO}_{2}$ after 12 months (Analysis 1.7).

\section{Secondary Outcomes}

\section{Quality of life}

Only one study investigated the effects of oxygen therapy on psychosocial, cognitive and behavioral aspects of daily living (Zinman 1989). Nocturnal oxygen therapy did not improve mood, esteem, or cognitive function, as determined by standardized questionnaires. Using a non-standardized structured questionnaire, significantly more participants receiving oxygen reported regular attendance at school or work after 6 and 12 months therapy, 10 out of 14 compared to 3 out of 14 and 10 out of 11 compared to 2 out of 10 respectively. Data at 6 and 12 months are presented in the graphs and give the following significant results, OR 9.17 (95\% Cl 1.63 to 51.43) and OR 40.00 (95\% Cl 3.05 to 524.83 ) respectively (Analysis 1.8). The paper reports that there was no change in maintenance of social contacts, fulfilment of daily management regimen or frequency of discussion of the impact of their illness (Zinman 1989).

\section{Sleep parameters}

Four studies measured changes in sleep parameters with oxygen therapy compared to room air (Gozal 1997; Milross 2001b; Parsons 1996; Spier 1984) (Analysis 1.9).

The percentage of total sleep time spent in REM sleep was significantly reduced with oxygen therapy compared to room air, MD -4.49 (95\% Cl -6.04 to -2.95) ( $\mathrm{P}<0.00001)$ (Gozal 1997; Parsons 1996; Spier 1984), but this was not the case for the percentage of total sleep time spent in non-REM sleep (Gozal 1997; Spier 1984). Sleep latency, ie the time taken to fall asleep after the start of the study, was also significantly reduced with oxygen therapy, MD -6.00 (95\% Cl -11.06 to -0.94$)(P=0.02)$ (Gozal 1997). The other sleep parameters that could be presented in the meta-analysis included total sleep time, (Gozal 1997; Spier 1984) and arousal index (Gozal 1997). Neither of these parameters was significantly affected by the use of oxygen therapy. 
Other outcomes were reported narratively by one study with no actual data that could be included in a meta-analysis (Parsons 1996). This study reported that there was no difference in respiratory disturbance index, sleep fragmentation, sleep efficiency, total sleep time and time in REM between the room air and low-flow oxygen groups. There was also no reported improvement in subjective sleep quality (Parsons 1996).

Upon inspection, the data from the Milross study appears to be skewed and thus can not be combined with the data from the other studies in a meta-analysis. Milross reported no change in total sleep time, sleep latency or arousals between room air and oxygen therapy (Milross 2001b). Neither did the investigators detect any change in sleep architecture (Milross 2001b).

Spier also reported on the number of sleep stage changes. There were an increased mean number of sleep stage changes in the room air group compared to the oxygen group, 10.1 changes compared to 8.1 changes $(P<0.05)$ (Spier 1984).

\section{Exercise tolerance}

Five studies measured exercise parameters with and without supplementary oxygen therapy (Falk 2006; Marcus 1992; McKone 2002; Nixon 1990; Shah 1997). One study used a submaximal exercise protocol only and took measurements after exercise (McKone 2002). Two studies measured during maximal exercise only (Marcus 1992; Shah 1997) and two studies recorded measurements both after submaximal exercise and during maximal exercise (Falk 2006; Nixon 1990).

\section{a. Submaximal exercise}

Three studies measured exercise parameters after submaximal exercise, but none of the results were significant (Analysis 1.10). The most common parameters to be reported were exercise tolerance, (McKone 2002); oxygen consumption, (McKone 2002; Nixon 1990); $\mathrm{CO}_{2}$ production, (Falk 2006; McKone 2002; Nixon 1990); minute ventilation, (Falk 2006; McKone 2002; Nixon 1990); and heart rate, (Falk 2006; McKone 2002; Nixon 1990). Of these variables, there were no significant differences between room air and supplementary oxygen.

\section{b. Maximal exercise}

Four studies reported exercise parameters during maximal exercise (Falk 2006; Marcus 1992; Nixon 1990; Shah 1997) (Analysis 1.11). Two of these studies reported on exercise duration; participants were able to exercise for a significantly longer duration with oxygen therapy, MD 1.03 minutes $(95 \% \mathrm{Cl} 0.11$ to 1.95$)(P=0.03)$ (Falk 2006; Marcus 1992). The ventilatory equivalent ( $\max V E / V O 2)$ was significantly higher in room air compared to oxygen therapy, MD -3.86 (95\% Cl -6.82 to -0.91) ( $\mathrm{P}=0.01$ ) (Falk 2006; Marcus 1992; Nixon 1990). None of the other parameters reported were significantly affected by supplementary oxygen compared with room air.

\section{Nutritional status}

Only one study examined the effect of oxygen therapy on objective measures of nutrition (Zinman 1989). The percentage change in ideal weight for height was not significant after 6 or 12 months therapy (Analysis 1.12).

\section{Changes in right heart function}

Only the Zinman study examined whether the use of chronic nocturnal oxygen therapy retarded the development of pulmonary hypertension and right-sided heart failure (Analysis 1.13). Six out of fourteen participants in the air group and four out of fourteen participants in the oxygen group developed at least one physical sign consistent with cor pulmonale. When entered into the metaanalysis, the result was not significant. No statistical analysis was mentioned in the original paper and subsequent follow up of participants who died outside the study period was incomplete (Zinman 1989).

Radionuclide angiography was performed on 24 participants (12 in each group). Both the placebo and oxygen group had detectable reductions in right ventricular ejection fraction (RVEF) and left ventricular ejection fraction (LVEF) at baseline, but there were no significant differences in these parameters after one year of oxygen therapy compared to placebo at rest or after exercise (Analysis 1.13).

\section{Costs of intervention}

None of the studies addressed cost issues, either directly or indirectly.

\section{Adverse effects}

The major adverse effect of oxygen therapy that investigators measured was an excessive increase in carbon dioxide levels. Comparisons between groups were made more difficult by the use of variations in protocol, duration of therapy and different methods of measurement. The degree of elevation in carbon dioxide during sleep or exercise was generally within $10 \mathrm{~mm} \mathrm{Hg}$ or $1.0 \mathrm{kPa}$. One study did report an average of $16 \mathrm{~mm} \mathrm{Hg}$ rise during exercise in the "Low Sat" group (Marcus 1992). It is unclear whether these rises are of clinical significance over time. Notably, the only paper to study long-term oxygen therapy did not discover an increase in $\mathrm{PaCO}_{2}$ after one year and reported not adverse clinical effects with the use of oxygen therapy (Zinman 1989).

No study reported local complications arising either from the use of oxygen or other problems relating to the method of administration of the study gas.

\section{DISCUSSION}

The frequency of the use of oxygen therapy in CF is unknown. We wished to examine the evidence for its potential benefit in CF.

Eleven studies were included in the review and ten of these were short-term. Nine of these studies were included in the original review and two were added at a later revision in 2008 (Barker 1998; Falk 2006). Six of the eleven studies reported the effects of oxygen supplementation on exercise performance in CF (Barker 1998; Falk 2006; Marcus 1992; McKone 2002; Nixon 1990; Shah 1997). Four other studies reported the effects of nocturnal oxygen supplementation on gas exchange and sleep quality (Gozal 1997; Milross 2001b; Parsons 1996; Spier 1984). A considerable number of outcomes were tested and to put the results in context, it should be noted that the results for the first two primary outcomes listed in this review were non-significant. The third primary outcome and some of the secondary outcomes did, however, show some 
significant differences between treatment and placebo groups which are worthy of discussion.

The results of the review of short-term studies showed that there was a statistically significant improvement in oxygen saturations during or immediately after exercise in participants with CF inspiring low-flow oxygen compared with room air. There was, however, a greater increase in both the transcutaneous and endtidal $\mathrm{CO}_{2}$ level while breathing low-flow oxygen during exercise compared to air. The clinical significance of this finding is unclear. During sleep, there was a significant improvement in oxygen saturation levels during both REM and non-REM sleep in those breathing low-flow oxygen. Data looking at changes in $\mathrm{CO}_{2}$ levels during sleep could not be combined in a meta-analysis, but greater increases in $\mathrm{CO}_{2}$ levels while breathing oxygen were reported in some studies. There was a significant reduction in percent of total sleep time spent in REM sleep and a reduced sleep onset latency during sleep with oxygen compared to air, but no significant changes in the mechanics of ventilation during sleep were found. Participants were able to exercise for a significantly longer duration while breathing oxygen compared to air, but no other significant effect on exercise tolerance was found.

One study looked at the long-term effects of oxygen in CF, and specifically described outcome measures including mortality, changes in lung function, gas exchange after 12 months, nutritional indices and progression of pulmonary hypertension (Zinman 1989). The participants received oxygen only during sleep. In participants followed for a mean duration of 26 months, nocturnal oxygen therapy did not affect any of the outcome variables. There was a trend towards improved right ventricular ejection fraction (RVEF) and cardiac output in the participants receiving oxygen but there was no clear relationship with better clinical outcome. Reasons for a lack of efficacy of oxygen could be explained by a number of the aspects of study design. The study population was relatively small, and may not have been of sufficient size to demonstrate statistical significance. Another reason may relate to the duration of oxygen therapy being too short to deliver a significant clinical benefit seven hours on average per day compared to the 12 to 24 hours of oxygen demonstrated in the original studies in COPD (MRC 1981; NOTTG 1980). The criterion for study entry included participants who were less severely hypoxemic than those in the COPD studies, which could easily have mixed those who would benefit with those with milder hypoxemia (Gorecka 1997). It is also conceivable that considering the different pulmonary pathophysiology in CF compared to COPD, there might be less therapeutic responsiveness to oxygen therapy.

Despite the presumed widespread use of oxygen therapy in CF, we believe that it is most frequently prescribed for people with documented arterial oxygen desaturation. Based on the successful use of long-term oxygen therapy in other conditions such as COPD, we hoped to find evidence to support the use of chronic oxygen therapy. We identified only one clinical study of chronic oxygen therapy which had a number of limitations and on this basis, there is an absence of evidence for benefit from long-term oxygen supplementation in people with advanced lung disease due to CF (Zinman 1989). It is possible that oxygen administered for longer daily durations in more uniformly severely ill individuals would prove to be beneficial.
With respect to oxygen supplementation during sleep in people with CF, it appears that hypoxemia can predictably be eliminated with variable degrees of hypercapnia resulting (Gozal 1997; Parsons 1996; Spier 1984). Based on the levels of hypercapnia noted in studies, there is no strong reason to suspect clinically important untoward side effects in the short term. We cannot be entirely sanguine about the potential effects of oxygen supplementation in all individuals with CF and advanced lung disease. Attention to blood gas analysis would be warranted in such individuals. In people with advanced hypercapnia in CF, nasal ventilation during sleep has become a common therapy (Hodson 1991; Moran 2007). There is no evidence of a consistently demonstrable improvement in sleep quality in people with CF given oxygen supplementation. However, the lack of benefit in the three single night studies in hospital sleep laboratories may derive in part from the artificial nature of the sleep environment. Further study may be warranted to assess sleep quality with oxygen therapy in these participants.

People with CF with advanced lung disease typically have reduced exercise tolerance, a fact corroborated in the four studies reviewed (Marcus 1992; McKone 2002; Nixon 1990; Shah 1997). Reduced exercise tolerance could be related to the underlying condition or ventilatory limits. However, it could also be related to hypoxemia, which can be treated with oxygen therapy. There is evidence of modest enhancement of exercise capacity and duration with oxygen supplementation, especially in participants with more advanced lung disease (Marcus 1992; McKone 2002; Nixon 1990). There is also a tendency for more hypercapnia during exercise when oxygen supplementation is administered, but once again, as with sleep, the degree of hypercapnia is unlikely to be of untoward clinical significance. In the one study that looked at recovery and subsequent exercise, people with CF do tend to recover more quickly when given oxygen supplementation after vigorous exercise and perform at a higher capacity with the next exercise challenge (Shah 1997). If the findings in these studies all of which examine short-term oxygen use were corroborated in longer-term use of oxygen in individuals with CF, improved fitness, muscle mass and well-being might well result. Certainly, this hypothesis would be a worthy one for future study.

\section{AUTHORS' CONCLUSIONS}

\section{Implications for practice}

To date, there is little evidence to support or oppose the longterm use of oxygen therapy to either reduce mortality or alleviate symptoms. The authors believe that no adequate study has examined this hypothesis with a rigorous enough study design to guide current prescribing practice. On the other hand, during sleep and exercise, there is evidence of modest improvements in oxygenation in hypoxemic people with $\mathrm{CF}$ with mild hypercapnia which probably has little clinical significance in the short term. Exercise capacity or duration or both are modestly improved in most participants. There is clearly a need for study of the potential benefit of long-term oxygen supplementation on the sleep quality and exercise parameters of individuals with CF.

Based on available data, oxygen therapy should be reserved for those individuals with objective evidence of hypoxemia, either at rest while awake or during either exercise or sleep. This review has found an absence of data on which to dictate the prescription of long-term oxygen therapy in people with CF with hypoxemia. In the subset of people with CF and documented nocturnal 
hypoxemia, oxygen therapy should be considered. In people with hypercapnia, assessment of the impact of oxygen supplementation on ventilation via capnometry may be indicated. In some of these individuals, nasal ventilation with oxygen supplementation during sleep may be a more optimal therapeutic choice. In people with CF with advanced lung disease and hypoxemia during exercise, the prescription of oxygen supplementation appears to prevent hypoxemia and has clear benefits regarding exercise capacity and duration. Although it is tempting to speculate that oxygen supplementation over time during exercise in people with CF with advanced lung disease might have cumulative benefits, there are no studies upon which to base this recommendation. Since there is some evidence that individuals with CF who have hypoxemia during exercise frequently have hypoxemia during sleep (Bradley 1999; Coffey 1991), overnight polysomnography should be considered in these individuals.

\section{Implications for research}

We recommend further multi-centre studies to determine a more precise role for both short-term and long-term limited (with exercise or during sleep) or continuous oxygen therapy in people with CF with hypoxemia. The studies included in this review were small and future studies should be adequately powered. For individuals with chronic hypoxemia, it would be of practical benefit to study the potential benefits of the long-term use of oxygen supplementation for the greater preponderance of each day (minimum of 16 hours per day). Regarding individuals with hypoxemia restricted to sleep, it would be beneficial to know if sleep quality improves in the home environment and whether oxygen supplementation improves survival, cardiopulmonary health, quality of life and nutrition without complications from hypercapnia. In individuals with hypoxemia during exercise, similarly it would be of interest to study the potential benefits of a rehabilitation program with oxygen supplementation compared to one without oxygen supplementation. Longitudinal studies would be expensive but would add weight to outcome measurement and allow for the many different confounders in this complex and multisystem disease.

The most recent trial included in the review was published in 2006, and we have not identified any relevant trials up to 2013. We therefore do not plan to update this review until the regular two-yearly searches of the Cochrane Cystic Fibrosis and Genetic Disorders Group's Cystic Fibrosis Trials Register identifies any new evidence.

\section{ACKNOWLEDGEMENTS}

The authors would like to thank the staff of the Cochrane Cystic Fibrosis and Genetic Disorders Group for guidance and patience during the extended period during which this project materialized. They would also like to thank Dr David Vaughan for his contribution to the protocol and Dr Jason Fullmer for his contribution to the first published version of the review. 


\section{RE F E R E N C E S}

\section{References to studies included in this review}

\section{Barker 1998 \{published data only\}}

Barker M, Wieching R, Hoffmann U, Ebfeld D, Kusenbach G. Effects of hyperoxia on oxygen uptake kinetics in cystic fibrosis patients and healthy controls [abstract]. European Respiratory Journal 1998;12(Suppl 28):391s.

\section{Falk 2006 \{published data only\}}

Falk B, Nini A, Zigel L, Yahav Y, Aviram M, Rivlin J, et al. Effect of low altitude at the Dead Sea on exercise capacity and cardiopulmonary response to exercise in cystic fibrosis patients with moderate to severe lung disease. Pediatric Pulmonology 2006;41(3):234-41.

\section{Gozal 1997 \{published data only\}}

Gozal D. Nocturnal ventilatory support in patients with cystic fibrosis: comparison with supplemental oxygen. European Respiratory Journal 1997;10(9):1999-2003.

\section{Marcus 1992 \{published data only\}}

Marcus CL, Bader D, Stabile MW, Wang C-I, Osher AB, Keens TG. Supplementation oxygen and exercise performance in patients with cystic fibrosis with severe pulmonary disease. Chest 1992;101(1):52-7.

\section{McKone 2002 \{published data only\}}

McKone EF, Barry S, Fitzgerald MX, Gallagher CG. The role of pulmonary mechanics and arterial hypoxaemia in exercise limitation in patients with severe cystic fibrosis [abstract]. American Journal of Respiratory and Critical Care Medicine 2000;161(3 Suppl):A228.

* McKone EF, Barry SC, FitzGerald MX, Gallagher CG. The role of supplemental oxygen during submaximal exercise in patients with cystic fibrosis. European Respiratory Journal 2002;20(1):134-42.

McKone EF, Barry SC, Fitzgerald MX, Gallagher CG. Role of arterial hypoxemia and pulmonary mechanics in exercise limitation in adults with cystic fibrosis. Journal of Applied Physiology 2005;99(3):1012-8.

\section{Milross 2001b \{published data only\}}

* Milross MA, Piper AJ, Norman M, Becker HF, Willson GN, Grunstein RR, et al. Low-flow oxygen and bilevel ventilatory support: effects on ventilation during sleep in cystic fibrosis. American Journal of Respiratory and Critical Care Medicine 2001;163(1):129-34.

Milross MA, Piper AJ, Norman M, Becker HF, Willson GN, Grunstein RR, et al. The effects of low flow oxygen and bilevel ventilatory support on gas exchange and ventilation during sleep in patients with cystic fibrosis [abstract]. Pediatric Pulmonology 1999;28 Suppl 19:285.

\section{Nixon 1990 \{published data only\}}

Nixon PA, Orenstein DM, Curtis SE, Ross EA. Oxygen supplementation during exercise in cystic fibrosis. American Review of Respiratory Disease 1990;142(4):807-11.

\section{Parsons 1996 \{published data only\}}

Parsons S, Grunstein R, Torzillo P, Sullivan C, Bye PTP. Nocturnal low-flow oxygen (nLFO2) improves oxyhaemoglobin saturation but not sleep function or carbon dioxide levels in patients with cystic fibrosis (CF) [abstract]. Australian \& New Zealand Journal of Medicine 1997;27:256

Parsons SW, Grunstein R, Sullivan CE, Bye PTP. The effects of nocturnal low-flow oxygen on sleep and gas exchange in patients with cystic fibrosis [abstract]. Pedriatric Pulmonology 1995;20 Suppl 12:251.

* Parsons SW, Grunstein R, Torzillo PJ, Sullivan CE, Bye PTP. The effects of nocturnal low-flow oxygen (nLFO2) on sleep function and gas exchange in patients with cystic fibrosis (CF) [abstract]. American Journal of Respiratory and Critical Care Medicine 1996;153(Suppl):A72.

\section{Shah 1997 \{published data only\}}

Shah AR, Keens TG, Gozal D. Effect of supplemental oxygen on anaerobic exercise performance and recovery in normals and cystic fibrosis [abstract]. American Journal of Respiratory and Critical Care Medicine 1996;153(Suppl):A652.

* Shah AR, Keens TG, Gozal D. Effect of supplemental oxygen on supramaximal exercise performance and recovery in cystic fibrosis. Journal of Applied Physiology 1997;83(5):1641-7.

\section{Spier 1984 \{published data only\}}

Spier S, Hughes D, Rivlin J, Levison H. Ventilatory and sleep responses to oxygen in cystic fibrosis patients [abstract]. 23rd Annual Meeting Cystic Fibrosis Club Abstracts; 1982 May 14; Washington D.C. 1982:65.

* Spier S, Rivlin J, Hughes D, Levison H. The effect of oxygen on sleep, blood gases, and ventilation in cystic fibrosis. The American Review of Respiratory Disease 1984;129:712-8.

\section{Zinman 1989 \{published data only\}}

* Zinman R, Corey M, Coates AL, Canny GJ, Connolly J, Levison $\mathrm{H}$, et al. Nocturnal home oxygen in the treatment of hypoxemic cystic fibrosis patients. Journal of Pediatrics 1989;114(3):368-77.

Zinman R, Corey M, Coates AL, Canny GJ, Connolly J, Levison H, et al. Nocturnal oxygen therapy in the treatment of hypoxemic cystic fibrosis patients [abstract]. Pediatric Pulmonology 1987;3(Suppl 3.1.3):73-4.

\section{References to studies excluded from this review}

Elkins 2004 \{published data only\}

Elkins MR, Eberl S, Alison J, Bye P. The effect of bi-level noninvasive ventilation on mucociliary clearance in subjects with cystic fibrosis [abstract]. Pediatric Pulmonology 2004;38 Suppl 27:315. 
Fauroux 1999 \{published data only\}

Fauroux B, Boule M, Lofaso F, Zerah F, Clement A, Harf A, et al. Chest physiotherapy in cystic fibrosis: improved tolerance with nasal pressure support ventilation. Pediatrics 1999;103(3):E32.

\section{Fauroux 2000 \{published data only\}}

Fauroux B, Itti E, Pigeot J, Isabey D, Meignan M, Ferry G, et al. Optimization of aerosol deposition by pressure support in children with cystic fibrosis: an experimental and clinical study. American Journal of Respiratory and Critical Care Medicine 2000;162(6):2265-71.

\section{Fauroux 2001 \{published data only\}}

Fauroux B, Pigeot J, Polkey MI, Isabey D, Clement A, Lofaso F. In vivo physiologic comparison of two ventilators used for domiciliary ventilation in children with cystic fibrosis. Critical Care Medicine 2001;29(11):2097-105

\section{Fauroux 2004 \{published data only\}}

Fauroux B, Louis B, Essouri S, Leroux K, Lofaso F. Back up rate during non invasive mechanical ventilation in cystic fibrosis [abstract]. European Respiratory Journal 2003;22(Suppl 45):262s.

* Fauroux B, Louis B, Hart N, Essouri S, Leroux K, Clement A, et al. The effect of back-up rate during non-invasive ventilation in young patients with cystic fibrosis. Intensive Care Medicine 2004;30(4):673-81.

\section{Holland 2003 \{published data only\}}

Holland A, Denehy L, Ntoumenopoulos G, McMeeken J, Wilson J. Non-invasive ventilation prevents inspiratory muscle fatigue and oxygen desaturation during airway clearance in adults with acute exacerbations of cystic fibrosis [abstract]. Proceedings of the Thoracic Society of Australia \& New Zealand Annual Scientific Meeting; 2003 April 4-9; Adelaide, Australia 2003. 2003:Abst \#P140.

Holland A, Denehy L, Ntoumenopoulos G, Naughton M, Wilson J. Non-invasive ventilation prevents inspiratory muscle fatigue and oxygen desaturation during airway clearance in adults with acute exacerbations of cystic fibrosis [abstract]. Journal of Cystic Fibrosis 2003;2 Suppl 1:S62.

Holland A, Denehy L, Ntoumenopoulos G, Wilson J. Noninvasive ventilation prevents inspiratory muscle fatigue and oxygen desaturation during airway clearance in adults with exacerbations of cystic fibrosis [abstract]. American Journal of Respiratory and Critical Care Medicine 2003;167:D041.

* Holland AE, Denehy L, Ntoumenopoulos G, Naughton MT, Wilson JW. Non-invasive ventilation assists chest physiotherapy in adults with acute exacerbations of cystic fibrosis. Thorax 2003;58(10):880-4.

\section{Placidi 2006 \{published data only\}}

Placidi G, Cornacchia M, Cappelletti LM, Mastella G, Assael BM, Braggion C. Short-term effects of positive airway pressure on sputum clearance by directed coughing: A cross-over, randomized study [abstract]. Pediatric Pulmonology 2001;32 Suppl 22:313-4.
* Placidi G, Cornacchia M, Polese G, Zanolla L, Assael BM, Braggion C. Chest physiotherapy with positive airway pressure: a pilot study of short-term effects on sputum clearance in patients with cystic fibrosis and severe airway obstruction. Respiratory Care 2006;51(10):1145-53.

\section{Riethmueller 2006 \{published data only\}}

Riethmueller J, Borth-Bruhns T, Kumpf M, Vonthein R, Wiskirchen J, Stern M, et al. Recombinant human deoxyribonuclease shortens ventilation time in young, mechanically ventilated children. Pediatric Pulmonology 2006;41(1):61-6.

\section{Serra 2002 \{published data only\}}

Serra A, Appendini L, Braggion C, Mastella G, Rossi A, Polese G. Noninvasive proportional assist ventilation (PAV) and pressure support ventilation (PSV) in patients with cystic fibrosis (CF): an overnight study [abstract]. American Journal of Respiratory and Critical Care Medicine 2000;161(3 Suppl):A555.

* Serra A, Polese G, Braggion C, Rossi A. Non-invasive proportional assist and pressure support ventilation in patients with cystic fibrosis and chronic respiratory failure. Thorax 2002;57(1):50-4.

\section{Stewart 2001 \{published data only\}}

Stewart IB, Sheel AW, Frangiolas DD, Wilcox PG, McKenzie DC. The effect of nitric oxide inhalation on pulmonary gas exchange and exercise capacity in patients with cystic fibrosis. Clinical Exercise Physiology 2001;3(1):44-8.

\section{Young 2008 \{published data only\}}

Young AC, Wilson JW, Kotsimbos TC, Naughton MT. Online Data Supplement to 'Randomised placebo controlled trial of noninvasive ventilation for hypercapnia in cystic fibrosis' [online]. Thorax 2008;63(1):72-7 online.

* Young AC, Wilson JW, Kotsimbos TC, Naughton MT. Randomised placebo controlled trial of non-invasive ventilation for hypercapnia in cystic fibrosis. Thorax 2008;63(1):72-7.

Young AC, Wilson JW, Kotsimbos TC, Naughton MT. Randomized placebo-controlled trial of non-invasive ventilation for hypercapnia in cystic fibrosis [abstract]. Proceedings of Japanese Society of Sleep Research Conference. 2006:A9-A10.

\section{Additional references}

\section{ATS 1991}

American Thoracic Society. Lung function testing: selection of reference values and interpretative strategies. American Review of Respiratory Disease 1991;144(5):1202-18.

\section{Bradley 1999}

Bradley S, Solin P, Wilson J, et al. Hypoxemia and hypercapnia during exercise and sleep in patients with cystic fibrosis. Chest 1999;100(3):647-54. 


\section{Coffey 1991}

Coffey MJ, FitzGerald MX, McNicholas WT. Comparison of oxygen desaturation during sleep and exercise in patients with cystic fibrosis. Chest 1991;100(3):659-62.

\section{Curtin 2002}

Curtin F, Altman DG, Elbourne D. Meta-analysis combining parallel and cross-over clinical trials. 1: Continuous outcomes. Statistics in Medicine 2002;21(15):2131-44.

\section{Elbourne 2002}

Elbourne DR, Altman DG, Higgins JPT, Curtin F, Worthington HV, Vail A. Meta-analysises involving cross-over trials: methodological issues. International Journal of Epidemiology 2002;31(1):140-9.

\section{Fitzsimmons 1996}

Fitzsimmons SC. The Cystic Fibrosis Foundation Patient Registry Report 1996. Pediatric Pulmonology 1996;21(Suppl):267-75.

\section{Frangiolis 2001}

Frangiolis DD, Wilcox PG. Predictability of oxygen desaturation during sleep in patients with cystic fibrosis. Chest 2001;119(2):434-41.

\section{Fraser 1999}

Fraser KL, Tullis DE, Sasson Z, Hyland RH, Thornley KS, Hanly PJ. Pulmonary hypertension and cardiac function in adult cystic fibrosis: role of hypoxemia. Chest 1999;115(5):1321-8.

\section{Frederiksen 1996}

Frederiksen B, Lanng S, Koch C, Hoiby N. Improved survival in the Danish center-treated cystic fibrosis patients: results of aggressive treatment. Pediatric Pulmonology 1996;21(3):149-50.

\section{Gong 1992}

Gong H. Air travel and oxygen therapy in cardiopulmonary patients. Chest 1992;101(4):1104-13.

\section{Gorecka 1997}

Gorecka D, Gorzelak K, Sliwinski P, Tobiasz M, Zielinski J. Effect of long-term oxygen therapy on survival in patients with chronic obstructive pulmonary disease with moderate hypoxaemia. Thorax 1997;52(8):674-9.

\section{Higgins 2003}

Higgins JPT, Thompson SG, Deeks JJ, Altman DG. Measuring inconsistency in meta-analyses. BMJ 2003;327(7414):557-60.

\section{Higgins 2009}

Higgins JPT, Altman DG. Chapter 8: Assessing risk of bias in included studies. In: Higgins JPT, Green S (editors). Cochrane Handbook of Systematic Reviews of Interventions. Version 5.0.2 [updated September 2009]. The Cochrane Collaboration, 2009. Available from www.cochrane-handbook.org. Cochrane Collaboration 2009.

\section{Hodson 1991}

Hodson ME, Madden BP, Steven MH, Tsang VT, Yacoub MH. Noninvasive mechanical ventilation for cystic fibrosis patients: a potential bridge to transplantation. European Respiratory Journal 1991;4(5):524-7.

\section{Milross 2001a}

Milross MA, Piper AJ, Norman M, Willson GN, Grunstein RR, et al. Predicting sleep-disordered breathing in patients with cystic fibrosis. Chest 2001;120(4):1239-45.

\section{Moran 2007}

Moran F, Bradley J. Non-invasive ventilation for cystic fibrosis. Cochrane Database of Systematic Reviews 2007, Issue 4. [DOI: 10.1002/14651858.CD002769.pub2]

\section{MRC 1981}

Report of the Medical Research Council Working Party. Long term domiciliary oxygen therapy in chronic hypoxic cor pulmonale complicating chronic bronchitis and emphysema. The Lancet 1981;8222(1):681-6.

\section{Narang 2003}

Narang I, Pike S, Rosenthal M, Balfour-Lynn IM, Bush A. Threeminute step test to assess exercise capacity in children with cystic fibrosis. Pediatric Pulmonology 2003;35(2):108-13.

\section{NOTTG 1980}

Nocturnal Oxygen Therapy Trial Group. Continuous or nocturnal oxygen therapy in hypoxemic chronic obstructive lung disease: a clinical trial. Annals of Internal Medicine 1980;93(3):391-8.

\section{Ramsey 1996}

Ramsey BW. Management of pulmonary disease in patients with cystic fibrosis. New England Journal of Medicine 1996;335(3):179-88.

\section{Schidlow 1993}

Schidlow DV, Taussig LM, Knowles MR. Cystic Fibrosis Foundation consensus conference report on pulmonary complications of cystic fibrosis. Pediatric Pulmonology 1993;15(3):187-98.

\section{Tarpy 1995}

Tarpy SP, Celli BR. Long-term oxygen therapy. New England Journal of Medicine 1995;333(11):710-4.

\section{Tepper 1983}

Tepper RA, Skatrud JB, Dempsey JA. Ventilation and oxygenation changes during sleep in cystic fibrosis. Chest 1983;84(2):388-93

\section{References to other published versions of this review Elphick 2009}

Elphick HE, Mallory G. Oxygen therapy for cystic fibrosis. Cochrane Database of Systematic Reviews 2009, Issue 1. [DOI: 10.1002/14651858.CD003884.pub3]

\section{Elphick 2013}

Elphick HE, Mallory G. Oxygen therapy for cystic fibrosis. Cochrane Database of Systematic Reviews 2013, Issue 7. [DOI: 10.1002/14651858.CD003884.pub4] 


\section{Mallory 2005}

Mallory GB, Vaughan D. Oxygen therapy for cystic fibrosis. Cochrane Database of Systematic Reviews 2005, Issue 2. [DOI: 10.1002/14651858.CD003884]

\section{Mallory 2009}

Mallory GB, Fullmer JJ, Vaughan DJ. Oxygen therapy for cystic fibrosis. Cochrane Database of Systematic Reviews 2009, Issue 1. [DOI: 10.1002/14651858.CD003884.pub2]

* Indicates the major publication for the study

\section{CHARACTERISTICS OF STUDIES}

Characteristics of included studies [ordered by study ID]

Barker 1998

\begin{tabular}{ll}
\hline Methods & Randomized controlled cross-over study, single center. \\
\hline Participants & 9 people with CF. \\
\hline Interventions & Submaximal exercise tests using cycle ergometry. \\
\hline Outcomes & Oxygen uptake, gas exchange and exercise parameters. \\
\hline Notes & No data recorded, abstract form only.
\end{tabular}

\section{Risk of bias}

\begin{tabular}{lll}
\hline Bias & Authors' judgement & Support for judgement \\
\hline $\begin{array}{l}\text { Random sequence genera- } \\
\text { tion (selection bias) }\end{array}$ & Unclear risk & $\begin{array}{l}\text { Reported that the order of interventions was randomized, but no details of the } \\
\text { method of randomization used. }\end{array}$ \\
\hline $\begin{array}{l}\text { Allocation concealment } \\
\text { (selection bias) }\end{array}$ & Unclear risk & No details of allocation concealment stated. \\
\hline $\begin{array}{l}\text { Blinding (performance } \\
\text { bias and detection bias) } \\
\begin{array}{l}\text { Participants } \\
\hline\end{array}\end{array}$ & Unclear risk & Degree of blinding not discussed. \\
\hline
\end{tabular}

Blinding (performance $\quad$ Unclear risk $\quad$ Degree of blinding not discussed.
bias and detection bias)

Clinicians

Blinding (performance $\quad$ Unclear risk $\quad$ Degree of blinding not discussed.
bias and detection bias)

Outcome assessors

$\begin{array}{ll}\begin{array}{l}\text { Incomplete outcome data } \\ \text { (attrition bias) }\end{array} & \text { Low risk } \\ \text { All outcomes } & \begin{array}{l}\text { Does not explicitly state that an intention-to-treat analysis was conducted. } \\ \text { However, data appear to have been analyzed based on all enrolled partici- } \\ \text { pants; states that all participants completed all the exercises. }\end{array}\end{array}$

Selective reporting (re- Unclear risk Survival is not specifically mentioned but there are data for all patients at the porting bias) end of the study.

Changes in gas exchange and exercise tolerance reported but no statement of statistical significance.

Other parameters not mentioned therefore assumed not measured.

\begin{tabular}{ll}
\hline Other bias $\quad$ Unclear risk $\quad$ No other bias mentioned \\
\hline
\end{tabular}


Falk 2006

\begin{tabular}{ll}
\hline Methods & Randomized controlled cross-over study, single center. \\
\hline Participants & 14 people with CF, 8 males, 6 females. Mean age 26.8 years (SD 7.1). \\
\hline Interventions & $\begin{array}{l}\text { Submaximal and maximal exercise tests in room air at sea level and at the Dead Sea (natural source of } \\
\text { oxygen enrichment). }\end{array}$ \\
\hline Outcomes & Gas exchange and exercise test parameters. \\
\hline Notes & \\
\hline
\end{tabular}

\section{Risk of bias}

\begin{tabular}{lll}
\hline Bias & Authors' judgement & Support for judgement \\
\hline $\begin{array}{l}\text { Random sequence genera- } \\
\text { tion (selection bias) }\end{array}$ & Unclear risk & $\begin{array}{l}\text { Reported that the order of interventions was randomized, but no details of the } \\
\text { method of randomization used. }\end{array}$ \\
\hline
\end{tabular}

\begin{tabular}{|c|c|c|}
\hline $\begin{array}{l}\text { Allocation concealment } \\
\text { (selection bias) }\end{array}$ & Unclear risk & No details of allocation concealment stated. \\
\hline $\begin{array}{l}\text { Blinding (performance } \\
\text { bias and detection bias) } \\
\text { Participants }\end{array}$ & High risk & $\begin{array}{l}\text { Study took place at sea level and at the Dead Sea and therefore participants } \\
\text { could not be blinded. }\end{array}$ \\
\hline $\begin{array}{l}\text { Blinding (performance } \\
\text { bias and detection bias) } \\
\text { Clinicians }\end{array}$ & High risk & $\begin{array}{l}\text { Study took place at sea level and at the Dead Sea and therefore investigators } \\
\text { could not be blinded. }\end{array}$ \\
\hline $\begin{array}{l}\text { Blinding (performance } \\
\text { bias and detection bias) } \\
\text { Outcome assessors }\end{array}$ & Unclear risk & Not mentioned. \\
\hline $\begin{array}{l}\text { Incomplete outcome data } \\
\text { (attrition bias) } \\
\text { All outcomes }\end{array}$ & Low risk & $\begin{array}{l}\text { Analyzed data on participants with less than } 15 \% \text { exclusions; data from } 3 \text { par- } \\
\text { ticipants not analysed as unable to complete the exercise tests. }\end{array}$ \\
\hline \multirow[t]{3}{*}{$\begin{array}{l}\text { Selective reporting (re- } \\
\text { porting bias) }\end{array}$} & Unclear risk & $\begin{array}{l}\text { Changes in lung function, changes in gas exchange and exercise tolerance re- } \\
\text { ported in full. }\end{array}$ \\
\hline & & $\begin{array}{l}\text { Survival is not specifically mentioned but there are data for all patients at the } \\
\text { end of the study. }\end{array}$ \\
\hline & & Other parameters not mentioned therefore assumed not measured. \\
\hline Other bias & Unclear risk & No other bias mentioned. \\
\hline
\end{tabular}

\section{Gozal 1997}

\begin{tabular}{ll}
\hline Methods & Randomized controlled cross-over study, single center. \\
\hline Participants & 6 people with CF, mean age 22.3 years ( $13-28$ years), 3 male, 3 female. \\
& Two participants dropped out due to inability to tolerate the face mask and BiPAP pressure titration.
\end{tabular}


Gozal 1997 (Continued)

Interventions PSG on 2 successive nights, FiO2 0.21 and 0.30 via nasal cannula, (3rd night with nasal BiPAP).

\begin{tabular}{ll}
\hline Outcomes & Total sleep, sleep quality and architecture, REM and NREM, SaO2, tPCO2. \\
\hline Notes & In-hospital PSG, data related to nasal BiPAP not included in analysis.
\end{tabular}

\section{Risk of bias}

\begin{tabular}{lll}
\hline Bias & Authors' judgement & Support for judgement \\
\hline $\begin{array}{l}\text { Random sequence genera- } \\
\text { tion (selection bias) }\end{array}$ & Unclear risk & $\begin{array}{l}\text { Reported that the order of interventions was randomized, but no details of the } \\
\text { method of randomization used. }\end{array}$
\end{tabular}

Allocation concealment $\quad$ Unclear risk $\quad$ No details of allocation concealment stated.
(selection bias)

\begin{tabular}{|c|c|c|}
\hline $\begin{array}{l}\text { Blinding (performance } \\
\text { bias and detection bias) }\end{array}$ & High risk & $\begin{array}{l}\text { Participants were aware of the nature of the intervention on the } 2 \text { nd and } 3 \text { rd } \\
\text { nights of the study (oxygen or NIPPV). }\end{array}$ \\
\hline
\end{tabular}

Participants

\section{High risk \\ Clinicians were aware of the nature of the intervention on the 2 nd and $3 \mathrm{rd}$ nights of the study (oxygen or NIPPV).}

Blinding (performance

bias and detection bias)

Clinicians

\begin{tabular}{lll}
\hline $\begin{array}{l}\text { Blinding (performance } \\
\text { bias and detection bias) } \\
\text { Outcome assessors }\end{array}$ & Unclear risk & Not mentioned. \\
\hline $\begin{array}{l}\text { Incomplete outcome data } \\
\text { (attrition bias) }\end{array}$ & Low risk & $\begin{array}{l}\text { 6 out of } 8 \text { participants completed the study; } 2 \text { participants were enrolled, but } \\
\text { later excluded from the study as they did not tolerate NIPPV. Not relevant to } \\
\text { this review as results for NIPPV not included in analysis. }\end{array}$ \\
\hline
\end{tabular}

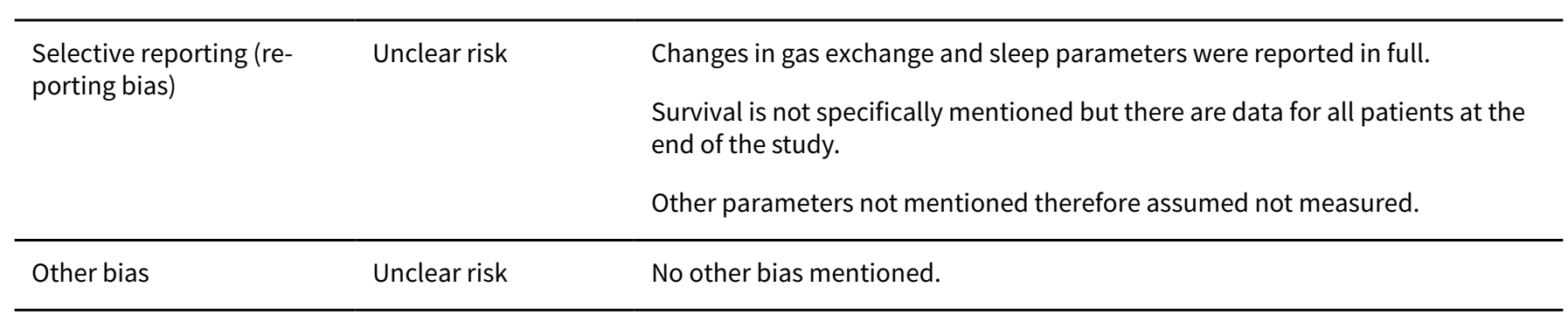

Marcus 1992

\begin{tabular}{ll}
\hline Methods & $\begin{array}{l}\text { Randomized controlled cross-over sstudy, single center. } \\
\text { Order of testing was randomized and participants were blinded to the composition of the inspired gas. }\end{array}$ \\
\hline Participants & $\begin{array}{l}22 \text { people with CF, median age } 26 \text { years (14 to } 46 \text { years), } 17 \text { male and } 5 \text { female, matched with } 21 \text { people } \\
\text { in a control group, median age } 29 \text { years (19 to } 37 \text { years), } 11 \text { male and } 10 \text { female. Test of } 1 \text { CF participant } \\
\text { terminated by physician. }\end{array}$
\end{tabular}

\begin{tabular}{ll}
\hline Interventions & 2 consecutive maximal exercise tests, FiO2 0.21 \& 0.30. \\
\hline Outcomes & VO2, duration of exercise, SaO2, PETCO2, tPCO2, VE, VCO2, HR, AT. \\
\hline Notes & \\
\hline
\end{tabular}


Marcus 1992 (Continued)

Risk of bias

\begin{tabular}{|c|c|c|}
\hline Bias & Authors' judgement & Support for judgement \\
\hline $\begin{array}{l}\text { Random sequence genera- } \\
\text { tion (selection bias) }\end{array}$ & Unclear risk & $\begin{array}{l}\text { Reported that the order of interventions was randomized, but no details of the } \\
\text { method of randomization used. }\end{array}$ \\
\hline $\begin{array}{l}\text { Allocation concealment } \\
\text { (selection bias) }\end{array}$ & Unclear risk & No details of allocation concealment stated. \\
\hline $\begin{array}{l}\text { Blinding (performance } \\
\text { bias and detection bias) } \\
\text { Participants }\end{array}$ & Low risk & Participants blinded to the type of therapy administered. \\
\hline $\begin{array}{l}\text { Blinding (performance } \\
\text { bias and detection bias) } \\
\text { Clinicians }\end{array}$ & Unclear risk & Not mentioned. \\
\hline $\begin{array}{l}\text { Blinding (performance } \\
\text { bias and detection bias) } \\
\text { Outcome assessors }\end{array}$ & Unclear risk & Not mentioned. \\
\hline $\begin{array}{l}\text { Incomplete outcome data } \\
\text { (attrition bias) } \\
\text { All outcomes }\end{array}$ & Unclear risk & $\begin{array}{l}\text { Analyzed data on participants with less than } 15 \% \text { exclusions; all but } 1 \text { partici- } \\
\text { pant completed the exercise tests, but not stated whether the results were an- } \\
\text { alyzed to include this participant. }\end{array}$ \\
\hline $\begin{array}{l}\text { Selective reporting (re- } \\
\text { porting bias) }\end{array}$ & Unclear risk & $\begin{array}{l}\text { Changes in gas exchange and exercise tolerance were reported in full. } \\
\text { Survival is not specifically mentioned but there are data for all patients at the } \\
\text { end of the study. } \\
\text { Other parameters not mentioned therefore assumed not measured. }\end{array}$ \\
\hline Other bias & Unclear risk & No other bias mentioned. \\
\hline
\end{tabular}

McKone 2002

\begin{tabular}{|c|c|c|}
\hline Methods & \multicolumn{2}{|c|}{ Randomized controlled cross-over study, single center. Single blind (participants). } \\
\hline Participants & \multicolumn{2}{|c|}{$\begin{array}{l}8 \text { people with CF, mean age } 26 \text { years, } 7 \text { male and } 1 \text { female. } \\
\text { Participants completed all three exercise tests and no test was stopped by the physician. }\end{array}$} \\
\hline Interventions & \multicolumn{2}{|c|}{$\begin{array}{l}\text { Two consecutive submaximal exercise tests, FiO2 } 0.21 \& 0.39 \text {. Order of control or oxygen tests was ran- } \\
\text { domized to avoid training effect. }\end{array}$} \\
\hline Outcomes & \multicolumn{2}{|c|}{ VO2, duration of exercise, SaO2, HR, VE. } \\
\hline \multicolumn{3}{|l|}{ Notes } \\
\hline \multicolumn{3}{|l|}{ Risk of bias } \\
\hline Bias & Authors' judgement & Support for judgement \\
\hline $\begin{array}{l}\text { Random sequence genera- } \\
\text { tion (selection bias) }\end{array}$ & Unclear risk & $\begin{array}{l}\text { Reported that the order of interventions was randomized, but no details of the } \\
\text { method of randomization used. }\end{array}$ \\
\hline
\end{tabular}


McKone 2002 (Continued)

Allocation concealment Unclear risk No details of allocation concealment stated.
(selection bias)

Blinding (performance Low risk Participants were blinded to the type of therapy administered.
bias and detection bias)
Participants

\begin{tabular}{|c|c|c|}
\hline $\begin{array}{l}\text { Blinding (performance } \\
\text { bias and detection bias) } \\
\text { Clinicians }\end{array}$ & High risk & $\begin{array}{l}\text { The primary investigator was not blinded. It is not clear whether this person } \\
\text { was also the outcome assessor. }\end{array}$ \\
\hline
\end{tabular}

\begin{tabular}{lll}
$\begin{array}{l}\text { Blinding (performance } \\
\text { bias and detection bias) } \\
\text { Outcome assessors }\end{array}$ & Unclear risk & See above. Not specifically mentioned. \\
\hline $\begin{array}{l}\text { Incomplete outcome data } \\
\begin{array}{l}\text { (attrition bias) } \\
\text { All outcomes }\end{array}\end{array}$ & Low risk & $\begin{array}{l}\text { Does not explicitly state that an intention-to-treat analysis was conducted. } \\
\text { However, data appear to have been analyzed based on all enrolled partici- } \\
\text { pants; states that all participants completed all the exercises. }\end{array}$
\end{tabular}

\begin{tabular}{ll}
\hline $\begin{array}{l}\text { Selective reporting (re- } \\
\text { porting bias) }\end{array}$ & Unclear risk \\
& $\begin{array}{l}\text { Changes in gas exchange and exercise tolerance were reported in full. } \\
\text { end of the study. }\end{array}$ \\
& $\begin{array}{l}\text { Lung function data were measured but analysis not reported. This may have } \\
\text { been because results were not significant. }\end{array}$ \\
& Other parameters not mentioned therefore assumed not measured.
\end{tabular}

\begin{tabular}{ll}
\hline Other bias $\quad$ Unclear risk $\quad$ No other bias mentioned. \\
\hline
\end{tabular}

Milross 2001b

\begin{tabular}{ll}
\hline Methods & Randomized controlled cross-over study. \\
\hline Participants & $\begin{array}{l}\text { 13 adults with CF, mean age } 26 \text { years. } \\
\text { Participants had moderate to severe lung disease (FEV1 less than 65\% of predicted), were in stable } \\
\text { clinical condition, and showed oxyhemoglobin desaturation to less then 90\% on baseline PSG. }\end{array}$ \\
\hline Interventions & On 3 nights, FiO2 0.21, titrated O2 via nasal cannula, and BiPAP with O2. \\
\hline Outcomes & Total sleep, sleep quality and architecture, SaO2, tPCO2, respiratory events, air flow via pneumotach. \\
\hline Notes & In-hospital PSG, data related to BiPAP not included in analysis. \\
\hline
\end{tabular}

\section{Risk of bias}

\begin{tabular}{lll}
\hline Bias & Authors' judgement & Support for judgement \\
\hline $\begin{array}{l}\text { Random sequence genera- } \\
\text { tion (selection bias) }\end{array}$ & Unclear risk & $\begin{array}{l}\text { Reported that the order of interventions was randomized, but no details of the } \\
\text { method of randomization used. }\end{array}$ \\
\hline $\begin{array}{l}\text { Allocation concealment } \\
\text { (selection bias) }\end{array}$ & Unclear risk & No details of allocation concealment stated. \\
\hline
\end{tabular}


Milross 2001b (Continued)

Blinding (performance Unclear risk Degree of blinding not discussed. bias and detection bias)

Participants

Blinding (performance Unclear risk Degree of blinding not discussed.
bias and detection bias)
Clinicians

Blinding (performance Unclear risk Degree of blinding not discussed.

bias and detection bias)

Outcome assessors

Incomplete outcome data Unclear risk

(attrition bias)

All outcomes

Selective reporting (re- Unclear risk

porting bias)
Incomplete arterial blood gas measurements for 4 participants; unclear if the results reported are for all participants.

Data were reported for gas exchange and sleep parameters. However, upon inspection the data appear skewed and cannot be included in meta-analysis.

Survival is not specifically mentioned but there are data for all patients at the end of the study.

Other parameters not mentioned therefore assumed not measured.

Other bias Unclear risk No other bias mentioned.

Nixon 1990

\begin{tabular}{ll}
\hline Methods & Randomized double-blind, cross-over study, single center. \\
\hline Participants & $\begin{array}{l}36 \text { people with CF. Equal number of participants with FEV1 }>50 \% \text { FVC and FEV1 }<50 \% \text { FVC recruited. } \\
\text { Participants divided into "Low Sat" group versus "High Sat" group. Low sat group: mean age 20.8 +/- } \\
4.5 \text { years, } 9 \text { male and } 6 \text { female. "High Sat" group: mean age } 13.9+/-4.1 \text { years, } 13 \text { male and } 6 \text { female. } \\
2 \text { younger participants excluded from results as unable to co-operate sufficiently. }\end{array}$ \\
\hline Interventions & 2 consecutive maximal exercise tests, FiO2 0.21 \& 0.30. \\
\hline Outcomes & Work rate, O2 consumption, HR, SaO2, ETCO2, VE. \\
\hline Notes &
\end{tabular}

\section{Risk of bias}

\begin{tabular}{lll}
\hline Bias & Authors' judgement & Support for judgement \\
\hline $\begin{array}{l}\text { Random sequence genera- } \\
\text { tion (selection bias) }\end{array}$ & Unclear risk & $\begin{array}{l}\text { Reported that the order of interventions was randomized, but no details of the } \\
\text { method of randomization used. }\end{array}$ \\
\hline $\begin{array}{l}\text { Allocation concealment } \\
\text { (selection bias) }\end{array}$ & Unclear risk & No details of allocation concealment stated. \\
\hline $\begin{array}{l}\text { Blinding (performance } \\
\text { bias and detection bias) } \\
\begin{array}{l}\text { Participants } \\
\hline\end{array}\end{array}$ & Low risk & $\begin{array}{l}\text { Both the participants and the supervising clinician were blinded to the gas } \\
\text { mixture received. }\end{array}$ \\
\hline
\end{tabular}


Nixon 1990 (Continued)

Blinding (performance Low risk Both the participants and the supervising clinician were blinded to the gas bias and detection bias) mixture received.

Clinicians

Blinding (performance $\quad$ Unclear risk Not mentioned.
bias and detection bias)
Outcome assessors

\begin{tabular}{|c|c|c|}
\hline $\begin{array}{l}\text { Incomplete outcome data } \\
\text { (attrition bias) } \\
\text { All outcomes }\end{array}$ & Unclear risk & $\begin{array}{l}\text { Analyzed data on participants with less than } 15 \% \text { exclusions; data from } 2 \text { par- } \\
\text { ticipants not analyzed, as they were too young to co-operate sufficiently. Un- } \\
\text { clear as to whether they were from the same group, therefore unclear as to } \\
\text { whether their withdrawal led to a risk of bias. }\end{array}$ \\
\hline
\end{tabular}

\begin{tabular}{|c|c|c|}
\hline $\begin{array}{l}\text { Selective reporting (re- } \\
\text { porting bias) }\end{array}$ & Unclear risk & $\begin{array}{l}\text { Changes in gas exchange and exercise tolerance were reported in full. } \\
\text { Survival is not specifically mentioned but there are data for all patients at the } \\
\text { end of the study. }\end{array}$ \\
\hline & & Other parameters not mentioned therefore assumed not measured. \\
\hline Other bias & Unclear risk & No other bias mentioned. \\
\hline
\end{tabular}

Parsons 1996

\begin{tabular}{ll}
\hline Methods & Randomized cross-over study, single center. \\
\hline Participants & $\begin{array}{l}11 \text { people with CF with severe lung disease age } 13 \text { to } 36 \text { years. Only } 7 \text { participants had blood gases tak- } \\
\text { en prior to the first study and upon wakening after each study. }\end{array}$ \\
\hline Interventions & On 2 consecutive nights, nasal cannula delivering FiO2 $0.21 \& 0.30$. \\
\hline Outcomes & Total sleep, sleep quality and architecture, SaO2, tPCO2, respiratory events. \\
\hline Notes & In-hospital PSG.
\end{tabular}

\section{Risk of bias}

\begin{tabular}{|c|c|c|}
\hline Bias & Authors' judgement & Support for judgement \\
\hline $\begin{array}{l}\text { Random sequence genera- } \\
\text { tion (selection bias) }\end{array}$ & Unclear risk & $\begin{array}{l}\text { Reported that the order of interventions was randomized, but no details of the } \\
\text { method of randomization used. }\end{array}$ \\
\hline $\begin{array}{l}\text { Allocation concealment } \\
\text { (selection bias) }\end{array}$ & Unclear risk & No details of allocation concealment stated. \\
\hline $\begin{array}{l}\text { Blinding (performance } \\
\text { bias and detection bias) } \\
\text { Participants }\end{array}$ & Unclear risk & Degree of blinding not discussed. \\
\hline $\begin{array}{l}\text { Blinding (performance } \\
\text { bias and detection bias) } \\
\text { Clinicians }\end{array}$ & Unclear risk & Degree of blinding not discussed. \\
\hline $\begin{array}{l}\text { Blinding (performance } \\
\text { bias and detection bias) } \\
\text { Outcome assessors }\end{array}$ & Unclear risk & Degree of blinding not discussed. \\
\hline
\end{tabular}


Parsons 1996 (Continued)

Incomplete outcome data Unclear risk Not clear if the results reported are from all 11 participants or just the 7 who (attrition bias) had arterial blood gas measurements taken prior to the first part of the study All outcomes and after each subsequent part.

Selective reporting (re- Unclear risk Changes in gas exchange and some sleep parameters were reported in full. porting bias)

Survival is not specifically mentioned but there are data for all patients at the end of the study.

Other parameters not mentioned therefore assumed not measured.

Other bias Unclear risk No other bias mentioned.

Shah 1997

\begin{tabular}{ll}
\hline Methods & Randomized controlled cross-over study, single center. Single blind (participants). \\
\hline Participants & $\begin{array}{l}17 \text { people with CF, mean age } 25 \text { years, } 9 \text { male and } 8 \text { female. } 17 \text { people in control group, mean age } 25 \\
\text { years, } 10 \text { male and } 7 \text { female. States each participant performed exercise before and after } 02 .\end{array}$ \\
\hline Interventions & 2 consecutive supramaximal exercise tests with recovery FiO2 0.21 or 0.30, then repeat exercise. \\
\hline Outcomes & VO2max, HR, VE, SaO2, peak work, exercise time, AT, subsequent work performance. \\
\hline Notes & \\
\hline
\end{tabular}

\section{Risk of bias}

\begin{tabular}{|c|c|c|}
\hline Bias & Authors' judgement & Support for judgement \\
\hline $\begin{array}{l}\text { Random sequence genera- } \\
\text { tion (selection bias) }\end{array}$ & Unclear risk & $\begin{array}{l}\text { Reported that the order of interventions was randomized, but no details of the } \\
\text { method of randomization used. }\end{array}$ \\
\hline $\begin{array}{l}\text { Allocation concealment } \\
\text { (selection bias) }\end{array}$ & Unclear risk & No details of allocation concealment stated. \\
\hline $\begin{array}{l}\text { Blinding (performance } \\
\text { bias and detection bias) } \\
\text { Participants }\end{array}$ & Low risk & Participants blinded to the type of therapy administered. \\
\hline $\begin{array}{l}\text { Blinding (performance } \\
\text { bias and detection bias) } \\
\text { Clinicians }\end{array}$ & Unclear risk & Not mentioned. \\
\hline $\begin{array}{l}\text { Blinding (performance } \\
\text { bias and detection bias) } \\
\text { Outcome assessors }\end{array}$ & Unclear risk & Not mentioned. \\
\hline $\begin{array}{l}\text { Incomplete outcome data } \\
\text { (attrition bias) } \\
\text { All outcomes }\end{array}$ & Low risk & $\begin{array}{l}\text { Does not explicitly state that an intention-to-treat analysis was conducted. } \\
\text { However, data appear to have been analyzed based on all enrolled partici- } \\
\text { pants; states that all participants completed all the exercises. }\end{array}$ \\
\hline $\begin{array}{l}\text { Selective reporting (re- } \\
\text { porting bias) }\end{array}$ & Unclear risk & $\begin{array}{l}\text { Changes in gas exchange and exercise tolerance were reported in full. } \\
\text { Survival is not specifically mentioned but there are data for all patients at the } \\
\text { end of the study. }\end{array}$ \\
\hline
\end{tabular}


Shah 1997 (Continued)

Other parameters not mentioned therefore assumed not measured.

Other bias Unclear risk No other bias mentioned.

Spier 1984

\begin{tabular}{ll}
\hline Methods & Randomized cross-over study, single center. \\
\hline Participants & $\begin{array}{l}\text { 8 people with CF, mean age 22, } 5 \text { males and } 3 \text { females, all with severe lung disease. Selected for the } \\
\text { study if in stable clinical state and } \mathrm{SaO} 2 \text { less than } 92 \% \text { on random arterial blood gas. } \\
10 \text { participants initially recruited, } 2 \text { participants analyzed separately due to history of snoring. }\end{array}$ \\
\hline Interventions & Nasal cannula during sleep with FiO2 $0.21 \& 0.31$ on 2 consecutive nights. \\
\hline Outcomes & Measures of sleep quality, tPCO2 and SaO2, respiratory events. \\
\hline Notes & In-hospital PSG.
\end{tabular}

\section{Risk of bias}

\begin{tabular}{lll} 
Bias & Authors' judgement & Support for judgement \\
\hline $\begin{array}{l}\text { Random sequence genera- } \\
\text { tion (selection bias) }\end{array}$ & Unclear risk & $\begin{array}{l}\text { Reported that the order of interventions was randomized, but no details of the } \\
\text { method of randomization used. }\end{array}$ \\
\hline
\end{tabular}

\begin{tabular}{lll}
\hline $\begin{array}{l}\text { Allocation concealment } \\
\text { (selection bias) }\end{array}$ & Unclear risk & No details of allocation concealment stated. \\
\hline $\begin{array}{l}\text { Blinding (performance } \\
\text { bias and detection bias) } \\
\text { Participants }\end{array}$ & Unclear risk & Degree of blinding not discussed. \\
\hline
\end{tabular}

Blinding (performance Unclear risk Degree of blinding not discussed.

bias and detection bias)

Clinicians

Blinding (performance $\quad$ Unclear risk $\quad$ Degree of blinding not discussed.
bias and detection bias)
Outcome assessors

\begin{tabular}{ll}
\hline $\begin{array}{l}\text { Incomplete outcome data } \\
\text { (attrition bias) }\end{array}$ & Low risk \\
All outcomes & $\begin{array}{l}\text { Data analyzed on all enrolled participants. Two participants had obstructive } \\
\text { sleep apnea symptoms and were mentioned separately but still included in } \\
\text { the analysis. }\end{array}$
\end{tabular}

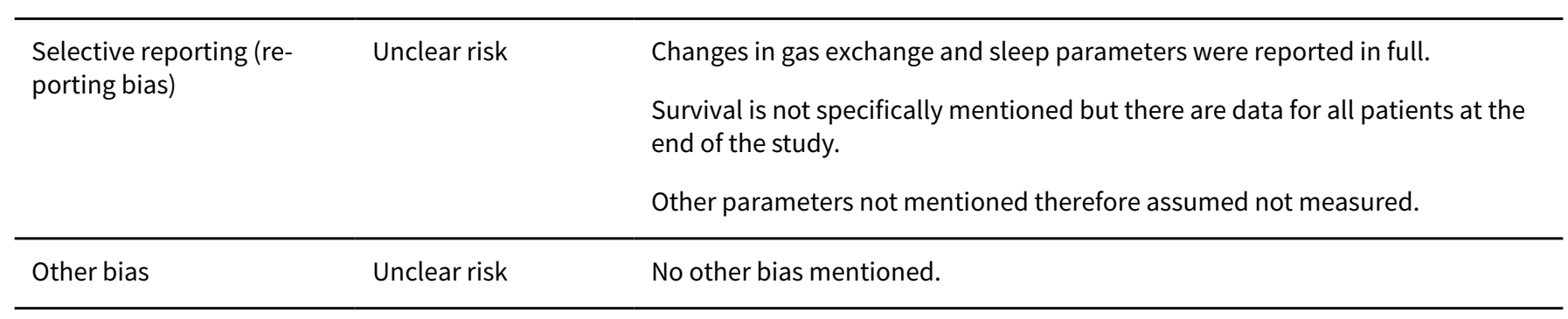


Zinman 1989

\begin{tabular}{ll}
\hline Methods & Multicenter randomized double-blind parallel controlled study. \\
\hline Participants & $\begin{array}{l}28 \text { people with CF older than } 12 \text { years of age. Oxygen group mean age } 23+/-6.7 \text { years, air group mean } \\
\text { age } 22.1+/-4.9 \text { years. } 9 \text { males and } 5 \text { females in each group. } \\
\text { All participants with FEF } 25-75<25 \% \text { predicted, and whose awake arterialized capillary PO2 < } 65 \text { mm } \\
\text { Hg on } 2 \text { occasions. } \\
10 \text { patients dropped out voluntarily (4 in oxygen group). O2 group (10 completed study): dropouts } 2 \\
\text { died during follow-up; } 2 \text { survived. Air group ( } 8 \text { completed study, all alive at follow-up): dropouts } 4 \text { died } \\
\text { at follow-up; } 2 \text { survived. }\end{array}$ \\
\hline Onterventions & O2 therapy or room air gas at night only, titrated to increase awake PaO2 $>70 \mathrm{~mm} \mathrm{Hg.}$ \\
\hline Outcomes & Mortality, lung function, anthropometrics, RAG, psychosocial questionnaire. \\
\hline Notes & O2 given only during sleep, average 7 hours.
\end{tabular}

\section{Risk of bias}

\begin{tabular}{lll}
\hline Bias & Authors' judgement & Support for judgement \\
\hline $\begin{array}{l}\text { Random sequence genera- } \\
\text { tion (selection bias) }\end{array}$ & Unclear risk & $\begin{array}{l}\text { Reported that the order of interventions was randomized, but no details of the } \\
\text { method of randomization used. }\end{array}$ \\
\hline $\begin{array}{l}\text { Allocation concealment } \\
\text { (selection bias) }\end{array}$ & Unclear risk & No details of allocation concealment stated. \\
\hline
\end{tabular}

\begin{tabular}{lll}
$\begin{array}{l}\text { Blinding (performance } \\
\text { bias and detection bias) } \\
\text { Participants }\end{array}$ & Low risk & Participants were blinded to the gas mixture received. \\
\hline $\begin{array}{l}\text { Blinding (performance } \\
\text { bias and detection bias) } \\
\text { Clinicians }\end{array}$ & Low risk & $\begin{array}{l}\text { In hospital, oxygen therapy was at the discretion of the supervising clinician; at } \\
\text { home the physician was obliged to "respect the blind nature of the study". }\end{array}$ \\
\hline $\begin{array}{l}\text { Blinding (performance } \\
\text { bias and detection bias) } \\
\text { Outcome assessors }\end{array}$ & Unclear risk & Not mentioned. \\
\hline
\end{tabular}

Incomplete outcome data Low risk (attrition bias)

All outcomes
Data were analyzed both on an intention-to-treat basis and on the 18 participants who completed the study (10 dropped out - 4 from the oxygen group and 6 from the room air group).

Follow-up of all participants with respect to survival data was complete.

\section{Selective reporting (re- Unclear risk} porting bias)

Survival data, changes in lung function, changes in gas exchange, quality of life, Wmax, nutritional status and changes in pulmonary artery pressure were reported in full.

Other parameters not mentioned therefore assumed not measured.

Other bias Unclear risk No other bias mentioned.

AT: anaerobic threshold

BiPAP: bi-level positive airway pressure ventilation

CF: cystic fibrosis

ETCO2: end tidal $\mathrm{CO} 2$, measure of carbon dioxide in exhaled gas

FiO2: fraction of inspired oxygen, or the percent of oxygen in the inspired gas

HR: heart rate 
NIPPV: non-invasive positive pressure ventilation

NREM: non-REM sleep

O2: oxygen

PaO2: partial pressure of oxygen in arterial blood

PETCO2: the maximum partial pressure of carbon dioxide exhaled during a tidal breath (just prior to the beginning of inspiration)

PSG: polysomnography

RAG: radionuclide angiography

REM: rapid eye movement sleep

$\mathrm{SaO2}$ : saturation of haemoglobin with oxygen using pulse oximetry

tPCO2:Partial pressure of carbon dioxide measured transcutaneously

VCO2: carbon dioxide production

VE: mean total ventilation

VO2: oxygen uptake

VO2max: maximal oxygen uptake

Characteristics of excluded studies [ordered by study ID]

\begin{tabular}{ll}
\hline Study & Reason for exclusion \\
\hline Elkins 2004 & Comparison of two modes of ventilation, not oxygen supplementation. \\
\hline Fauroux 1999 & Comparison of chest physiotherapy with and without pressure support, not oxygen. \\
\hline Fauroux 2000 & Comparison of aerosolisation with and without pressure support, not oxygen. \\
\hline Fauroux 2001 & Comparison of two modes of ventilation, not oxygen supplementation. \\
\hline Fauroux 2004 & Comparison of two modes of ventilation, not oxygen supplementation. \\
\hline Holland 2003 & Comparison of two airway clearance techniques, not oxygen supplementation. \\
\hline Placidi 2006 & Comparison of chest physiotherapy with and without pressure support, not oxygen. \\
\hline Riethmueller 2006 & Comparison of rhDNAse with and without ventilation, not oxygen. \\
\hline Serra 2002 & $\begin{array}{l}\text { Study of nasal ventilation with oxygen supplementation contaminates potential impact of oxygen } \\
\text { supplementation alone. }\end{array}$ \\
\hline Stewart 2001 & Cycle ergometer tests using compressed air with 20 ppm No versus compressed air only. \\
\hline Young 2008 & Comparison of two modes of ventilation, not oxygen supplementation. \\
\hline
\end{tabular}

NO: nitric oxide

ppm: parts per million

rhDNAse: recombinant human deoxyribonuclease

\section{DATA AND ANALYSES}




\section{Comparison 1. Oxygen therapy versus control}

\begin{tabular}{|c|c|c|c|c|}
\hline Outcome or subgroup title & $\begin{array}{l}\text { No. of } \\
\text { studies }\end{array}$ & $\begin{array}{l}\text { No. of } \\
\text { partici- } \\
\text { pants }\end{array}$ & Statistical method & Effect size \\
\hline 1 Survival & 1 & & $\begin{array}{l}\text { Odds Ratio (M-H, Fixed, 95\% } \\
\mathrm{Cl})\end{array}$ & Totals not selected \\
\hline 1.1 Deaths at 36 months & 1 & & $\begin{array}{l}\text { Odds Ratio (M-H, Fixed, 95\% } \\
\mathrm{Cl})\end{array}$ & $0.0[0.0,0.0]$ \\
\hline 2 Change in FEV1 & 1 & & $\begin{array}{l}\text { Mean Difference (IV, Fixed, } \\
95 \% \mathrm{CI})\end{array}$ & Totals not selected \\
\hline 2.1 At 6 months & 1 & & $\begin{array}{l}\text { Mean Difference (IV, Fixed, } \\
95 \% \mathrm{CI})\end{array}$ & $0.0[0.0,0.0]$ \\
\hline 2.2 At 12 months & 1 & & $\begin{array}{l}\text { Mean Difference (IV, Fixed, } \\
95 \% \mathrm{CI} \text { ) }\end{array}$ & $0.0[0.0,0.0]$ \\
\hline 3 Change in FVC & 1 & & $\begin{array}{l}\text { Mean Difference (IV, Fixed, } \\
95 \% \mathrm{CI} \text { ) }\end{array}$ & Totals not selected \\
\hline 3.1 At 6 months & 1 & & $\begin{array}{l}\text { Mean Difference (IV, Fixed, } \\
95 \% \mathrm{CI} \text { ) }\end{array}$ & $0.0[0.0,0.0]$ \\
\hline 3.2 At 12 months & 1 & & $\begin{array}{l}\text { Mean Difference (IV, Fixed, } \\
95 \% \mathrm{CI})\end{array}$ & $0.0[0.0,0.0]$ \\
\hline 4 Change in gas exchange during exercise & 5 & & $\begin{array}{l}\text { Mean Difference (IV, Fixed, } \\
95 \% \mathrm{CI} \text { ) }\end{array}$ & Subtotals only \\
\hline 4.1 Post exercise $\mathrm{SaO} 2(\%)$ & 3 & 84 & $\begin{array}{l}\text { Mean Difference (IV, Fixed, } \\
95 \% \mathrm{CI} \text { ) }\end{array}$ & $2.11[1.54,2.68]$ \\
\hline 4.2 Post exercise PETCO2 $(\mathrm{mm} \mathrm{Hg})$ & 2 & 62 & $\begin{array}{l}\text { Mean Difference (IV, Fixed, } \\
95 \% \mathrm{CI} \text { ) }\end{array}$ & $0.11[-2.14,2.36]$ \\
\hline $\begin{array}{l}\text { 4.3 Change in } \mathrm{SaO} 2 \text { during maximal exercise } \\
(\%)\end{array}$ & 1 & 44 & $\begin{array}{l}\text { Mean Difference (IV, Fixed, } \\
95 \% \mathrm{CI})\end{array}$ & $7.0[2.61,11.39]$ \\
\hline $\begin{array}{l}\text { 4.4 Change in PETCO2 during maximal exercise } \\
(\mathrm{mm} \mathrm{Hg})\end{array}$ & 2 & 112 & $\begin{array}{l}\text { Mean Difference (IV, Fixed, } \\
95 \% \mathrm{CI})\end{array}$ & $3.71[1.28,6.14]$ \\
\hline $\begin{array}{l}\text { 4.5 Change in } \mathrm{tPCO} 2 \text { during maximal exercise } \\
(\mathrm{mm} \mathrm{Hg})\end{array}$ & 1 & 44 & $\begin{array}{l}\text { Mean Difference (IV, Fixed, } \\
95 \% \mathrm{Cl} \text { ) }\end{array}$ & $4.0[1.23,6.77]$ \\
\hline 4.6 SaO2 during maximal exercise (\%) & 3 & 108 & $\begin{array}{l}\text { Mean Difference (IV, Fixed, } \\
95 \% \mathrm{CI} \text { ) }\end{array}$ & $2.01[1.16,2.85]$ \\
\hline 5 Change in gas exchange during sleep & 3 & & $\begin{array}{l}\text { Mean Difference (IV, Fixed, } \\
95 \% \mathrm{CI})\end{array}$ & Subtotals only \\
\hline $5.1 \mathrm{SaO} 2$ in REM sleep (\%) & 2 & 34 & $\begin{array}{l}\text { Mean Difference (IV, Fixed, } \\
95 \% \mathrm{CI} \text { ) }\end{array}$ & $7.54[4.31,10.77]$ \\
\hline 5.2 tPCO2 in REM sleep ( $\mathrm{kPa})$ & 1 & 12 & $\begin{array}{l}\text { Mean Difference (IV, Fixed, } \\
95 \% \mathrm{CI})\end{array}$ & $1.0[0.15,1.85]$ \\
\hline
\end{tabular}




\begin{tabular}{|c|c|c|c|c|}
\hline Outcome or subgroup title & $\begin{array}{l}\text { No. of } \\
\text { studies }\end{array}$ & $\begin{array}{l}\text { No. of } \\
\text { partici- } \\
\text { pants }\end{array}$ & Statistical method & Effect size \\
\hline 5.3 TcPCO2 in REM sleep ( $\mathrm{mm} \mathrm{Hg}$ ) & 1 & 20 & $\begin{array}{l}\text { Mean Difference (IV, Fixed, } \\
95 \% \mathrm{CI} \text { ) }\end{array}$ & $0.30[-6.69,7.29]$ \\
\hline $5.4 \mathrm{SaO} 2$ in non-REM sleep (\%) & 1 & 12 & $\begin{array}{l}\text { Mean Difference (IV, Fixed, } \\
95 \% \mathrm{CI} \text { ) }\end{array}$ & $6.0[1.92,10.08]$ \\
\hline 5.5 tPCO2 in non-REM sleep ( $\mathrm{kPa})$ & 1 & 12 & $\begin{array}{l}\text { Mean Difference (IV, Fixed, } \\
95 \% \mathrm{CI})\end{array}$ & $0.70[-0.09,1.49]$ \\
\hline 5.6 TcPCO2 in non-REM sleep ( $\mathrm{mm} \mathrm{Hg}$ ) & 1 & 20 & $\begin{array}{l}\text { Mean Difference (IV, Fixed, } \\
95 \% \mathrm{CI})\end{array}$ & $-1.0[-6.51,4.51]$ \\
\hline 5.7 Maximum $\mathrm{TcCO} 2$ with total sleep $(\mathrm{mm} \mathrm{Hg})$ & 1 & 22 & $\begin{array}{l}\text { Mean Difference (IV, Fixed, } \\
95 \% \mathrm{CI})\end{array}$ & $5.0[-2.07,12.07]$ \\
\hline 6 Change in $\mathrm{PaO} 2$ & 1 & & $\begin{array}{l}\text { Mean Difference (IV, Fixed, } \\
95 \% \mathrm{CI} \text { ) }\end{array}$ & Totals not selected \\
\hline 6.1 At 12 months & 1 & & $\begin{array}{l}\text { Mean Difference (IV, Fixed, } \\
95 \% \mathrm{CI})\end{array}$ & $0.0[0.0,0.0]$ \\
\hline 7 Change in $\mathrm{PaCO} 2$ & 1 & & $\begin{array}{l}\text { Mean Difference (IV, Fixed, } \\
95 \% \mathrm{CI})\end{array}$ & Totals not selected \\
\hline 7.1 At 12 months & 1 & & $\begin{array}{l}\text { Mean Difference (IV, Fixed, } \\
95 \% \mathrm{CI})\end{array}$ & $0.0[0.0,0.0]$ \\
\hline $\begin{array}{l}8 \text { Quality of life: regular attendance at school } \\
\text { or work }\end{array}$ & 1 & & $\begin{array}{l}\text { Odds Ratio (M-H, Fixed, 95\% } \\
\text { Cl) }\end{array}$ & Totals not selected \\
\hline 8.1 At 6 months & 1 & & $\begin{array}{l}\text { Odds Ratio (M-H, Fixed, 95\% } \\
\mathrm{Cl} \text { ) }\end{array}$ & $0.0[0.0,0.0]$ \\
\hline 8.2 At 12 months & 1 & & $\begin{array}{l}\text { Odds Ratio (M-H, Fixed, 95\% } \\
\mathrm{Cl})\end{array}$ & $0.0[0.0,0.0]$ \\
\hline 9 Sleep parameters & 3 & & $\begin{array}{l}\text { Mean Difference (IV, Fixed, } \\
95 \% \mathrm{CI})\end{array}$ & Subtotals only \\
\hline 9.1 Percent of total sleep time in REM sleep (\%) & 3 & 50 & $\begin{array}{l}\text { Mean Difference (IV, Fixed, } \\
95 \% \mathrm{CI})\end{array}$ & $-4.49[-6.04,-2.95]$ \\
\hline $\begin{array}{l}\text { 9.2 Percent of total sleep time in non-REM } \\
\text { sleep }\end{array}$ & 2 & 28 & $\begin{array}{l}\text { Mean Difference (IV, Fixed, } \\
95 \% \mathrm{CI})\end{array}$ & $2.89[-0.41,6.20]$ \\
\hline 9.3 Sleep latency (minutes) & 1 & 12 & $\begin{array}{l}\text { Mean Difference (IV, Fixed, } \\
95 \% \mathrm{CI})\end{array}$ & $-6.0[-11.06,-0.94]$ \\
\hline 9.4 Total sleep time (minutes) & 2 & 28 & $\begin{array}{l}\text { Mean Difference (IV, Fixed, } \\
95 \% \mathrm{CI})\end{array}$ & $1.93[-30.38,34.23]$ \\
\hline 9.5 Arousal index & 1 & 12 & $\begin{array}{l}\text { Mean Difference (IV, Fixed, } \\
95 \% \mathrm{CI} \text { ) }\end{array}$ & $-2.10[-4.28,0.08]$ \\
\hline
\end{tabular}




\begin{tabular}{|c|c|c|c|c|}
\hline Outcome or subgroup title & $\begin{array}{l}\text { No. of } \\
\text { studies }\end{array}$ & $\begin{array}{l}\text { No. of } \\
\text { partici- } \\
\text { pants }\end{array}$ & Statistical method & Effect size \\
\hline $\begin{array}{l}10 \text { Exercise parameters after submaximal exer- } \\
\text { cise }\end{array}$ & 3 & & $\begin{array}{l}\text { Mean Difference (IV, Fixed, } \\
95 \% \mathrm{CI})\end{array}$ & Subtotals only \\
\hline 10.1 Exercise duration (s) & 1 & 16 & $\begin{array}{l}\text { Mean Difference (IV, Fixed, } \\
95 \% \mathrm{CI})\end{array}$ & $163.0[-66.91,392.91]$ \\
\hline 10.2 Oxygen consumption (ml/kg/min) & 2 & 62 & $\begin{array}{l}\text { Mean Difference (IV, Fixed, } \\
95 \% \mathrm{CI})\end{array}$ & $-0.43[-2.06,1.20]$ \\
\hline $10.3 \mathrm{CO} 2$ production ( $\mathrm{l} / \mathrm{min})$ & 3 & 84 & $\begin{array}{l}\text { Mean Difference (IV, Fixed, } \\
95 \% \mathrm{CI})\end{array}$ & $-0.01[-0.11,0.09]$ \\
\hline 10.4 Minute ventilation $(\mathrm{l} / \mathrm{min})$ & 3 & 84 & $\begin{array}{l}\text { Mean Difference (IV, Fixed, } \\
95 \% \mathrm{CI} \text { ) }\end{array}$ & $-0.92[-3.36,1.53]$ \\
\hline 10.5 Heart rate (beats / min) & 3 & 84 & $\begin{array}{l}\text { Mean Difference (IV, Fixed, } \\
95 \% \mathrm{CI} \text { ) }\end{array}$ & $-3.96[-8.84,0.92]$ \\
\hline $\begin{array}{l}11 \text { Exercise parameters during maximal exer- } \\
\text { cise }\end{array}$ & 4 & & $\begin{array}{l}\text { Mean Difference (IV, Fixed, } \\
95 \% \mathrm{CI} \text { ) }\end{array}$ & Subtotals only \\
\hline 11.1 Exercise duration (min) & 2 & 72 & $\begin{array}{l}\text { Mean Difference (IV, Fixed, } \\
95 \% \mathrm{CI})\end{array}$ & $1.03[0.11,1.95]$ \\
\hline 11.2 Ventilatory equivalent (VE/VO2) & 3 & 118 & $\begin{array}{l}\text { Mean Difference (IV, Fixed, } \\
95 \% \mathrm{CI})\end{array}$ & $-3.86[-6.82,-0.91]$ \\
\hline 11.3 Maximum heart rate (beats / min) & 4 & 152 & $\begin{array}{l}\text { Mean Difference (IV, Fixed, } \\
95 \% \mathrm{CI})\end{array}$ & $-1.35[-6.05,3.35]$ \\
\hline $\begin{array}{l}\text { 11.4 Maximum oxygen consumption }(\mathrm{ml} / \mathrm{kg} / \\
\mathrm{min} \text { ) }\end{array}$ & 3 & 118 & $\begin{array}{l}\text { Mean Difference (IV, Fixed, } \\
95 \% \mathrm{CI})\end{array}$ & $0.92[-2.02,3.87]$ \\
\hline 11.5 Minute ventilation ( $\mathrm{l} / \mathrm{min})$ & 4 & 152 & $\begin{array}{l}\text { Mean Difference (IV, Fixed, } \\
95 \% \mathrm{CI})\end{array}$ & $-1.17[-7.06,4.73]$ \\
\hline 11.6 Ventilatory reserve utilisation (VE/MVV) & 2 & 74 & $\begin{array}{l}\text { Mean Difference (IV, Fixed, } \\
95 \% \mathrm{CI} \text { ) }\end{array}$ & $-0.05[-0.15,0.05]$ \\
\hline $\begin{array}{l}12 \text { Nutritional status: change in \% ideal body } \\
\text { weight for height }\end{array}$ & 1 & & $\begin{array}{l}\text { Mean Difference (IV, Fixed, } \\
95 \% \mathrm{CI} \text { ) }\end{array}$ & Totals not selected \\
\hline 12.1 At 6 months & 1 & & $\begin{array}{l}\text { Mean Difference (IV, Fixed, } \\
95 \% \mathrm{CI})\end{array}$ & $0.0[0.0,0.0]$ \\
\hline 12.2 At 12 months & 1 & & $\begin{array}{l}\text { Mean Difference (IV, Fixed, } \\
95 \% \mathrm{CI})\end{array}$ & $0.0[0.0,0.0]$ \\
\hline 13 Changes in right heart function & 1 & & $\begin{array}{l}\text { Odds Ratio (M-H, Fixed, 95\% } \\
\mathrm{Cl})\end{array}$ & Totals not selected \\
\hline 13.1 Clinical signs of cor pulmonale & 1 & & $\begin{array}{l}\text { Odds Ratio (M-H, Fixed, 95\% } \\
\mathrm{Cl} \text { ) }\end{array}$ & $0.0[0.0,0.0]$ \\
\hline
\end{tabular}




\begin{tabular}{lllll}
\hline Outcome or subgroup title & $\begin{array}{l}\text { No. of } \\
\text { studies }\end{array}$ & $\begin{array}{l}\text { No. of } \\
\text { partici- } \\
\text { pants }\end{array}$ & Statistical method & Effect size \\
\hline $\begin{array}{l}\text { 13.2 Abnormal rlght ventricular ejection frac- } \\
\text { tion at rest }\end{array}$ & 1 & & $\begin{array}{l}\text { Odds Ratio (M-H, Fixed, 95\% } \\
\mathrm{Cl})\end{array}$ & $0.0[0.0,0.0]$ \\
\hline $\begin{array}{l}13.3 \text { Abnormal right ejection fraction with exer- } \\
\text { cise }\end{array}$ & 1 & $\begin{array}{l}\text { Odds Ratio (M-H, Fixed, 95\% } \\
\mathrm{Cl})\end{array}$ & $0.0[0.0,0.0]$ \\
\hline
\end{tabular}

Analysis 1.1. Comparison 1 Oxygen therapy versus control, Outcome 1 Survival.

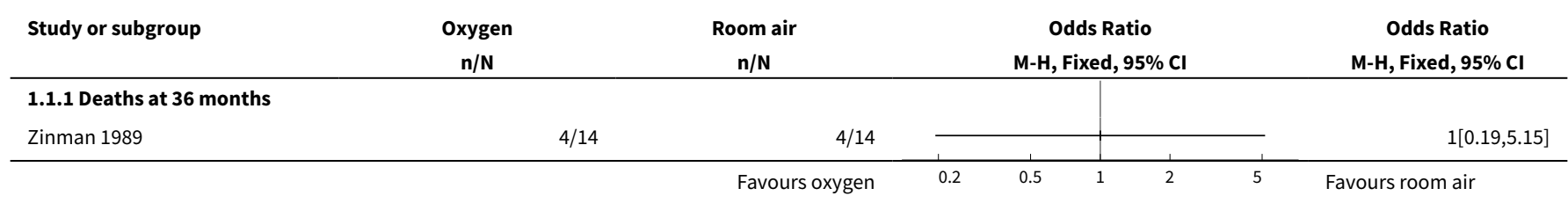

Analysis 1.2. Comparison 1 Oxygen therapy versus control, Outcome 2 Change in FEV1.

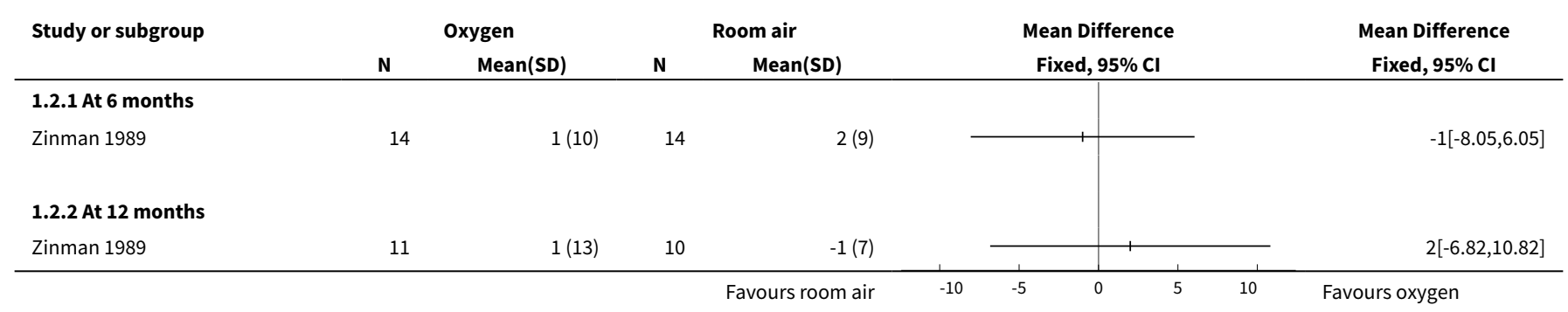

Analysis 1.3. Comparison 1 Oxygen therapy versus control, Outcome 3 Change in FVC.

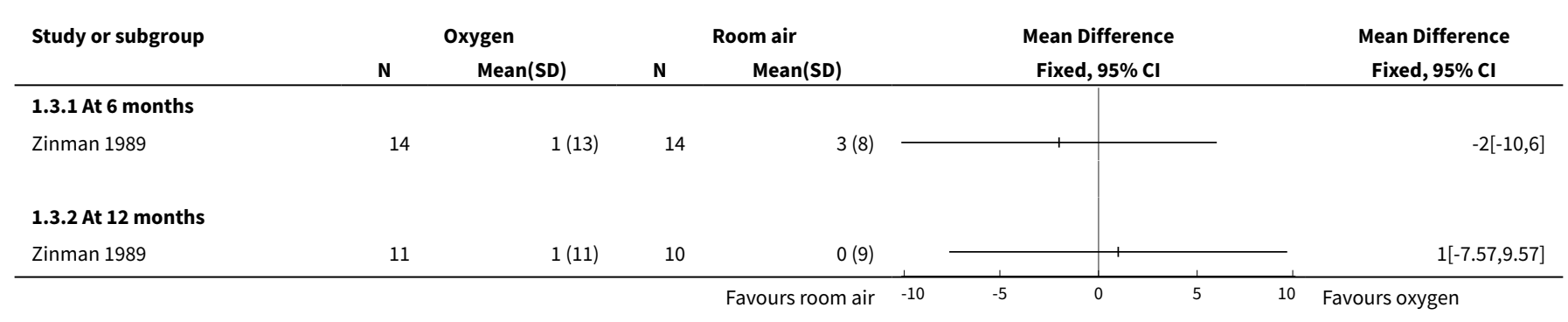


Analysis 1.4. Comparison 1 Oxygen therapy versus control, Outcome 4 Change in gas exchange during exercise.

\begin{tabular}{|c|c|c|c|c|}
\hline \multirow[t]{2}{*}{ Study or subgroup } & \multicolumn{2}{|c|}{ Oxygen } & \multicolumn{2}{|c|}{ Room air } \\
\hline & $\mathbf{N}$ & Mean(SD) & $\mathbf{N}$ & Mean(SD) \\
\hline \multicolumn{5}{|c|}{ 1.4.1 Post exercise SaO2 (\%) } \\
\hline Falk 2006 & 11 & $92.4(5.4)$ & 11 & $89.9(6.3)$ \\
\hline McKone 2002 & 8 & $96(3.3)$ & 8 & $86(6.6)$ \\
\hline Nixon 1990 & 23 & $97(1)$ & 23 & $95(1)$ \\
\hline Subtotal $\star \star \star$ & 42 & & 42 & \\
\hline
\end{tabular}

Heterogeneity: $\mathrm{Tau}^{2}=0 ; \mathrm{Chi}^{2}=9.31, \mathrm{df}=2(\mathrm{P}=0.01) ; \mathrm{I}^{2}=78.52 \%$

Test for overall effect: $Z=7.24(P<0.0001)$

\subsubsection{Post exercise PETCO2 $(\mathrm{mm} \mathrm{Hg})$}

\begin{tabular}{|c|c|c|c|}
\hline McKone 2002 & 8 & $43(11.3)$ & 8 \\
\hline Nixon 1990 & 23 & $36(4)$ & 23 \\
\hline 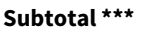 & 31 & & 31 \\
\hline
\end{tabular}

Heterogeneity: $\mathrm{Tau}^{2}=0 ; \mathrm{Chi}^{2}=0.15, \mathrm{df}=1(\mathrm{P}=0.7) ; \mathrm{I}^{2}=0 \%$

Test for overall effect: $Z=0.09(P=0.93)$

1.4.3 Change in SaO2 during maximal exercise (\%)

\begin{tabular}{|c|c|c|c|c|}
\hline Marcus 1992 & 22 & $-5(4.7)$ & 22 & $-12(9.4)$ \\
\hline Subtotal $\star \star \star$ & 22 & & 22 & \\
\hline \multicolumn{5}{|c|}{ Heterogeneity: Not applicable } \\
\hline \multicolumn{5}{|c|}{ Test for overall effect: $Z=3.12(P=0)$} \\
\hline \multicolumn{5}{|c|}{ 1.4.4 Change in PETCO2 during maximal exercise $(\mathrm{mm} \mathrm{Hg})$} \\
\hline Marcus 1992 & 22 & $16(9.4)$ & 22 & $10(4.7$ \\
\hline Nixon 1990 & 34 & $5.9(6.8)$ & 34 & $3.2(5$ \\
\hline Subtotal $* \star \star$ & 56 & & 56 & \\
\hline
\end{tabular}

Heterogeneity: Tau $^{2}=0 ; \mathrm{Chi}^{2}=1.51, \mathrm{df}=1(\mathrm{P}=0.22) ; \mathrm{I}^{2}=33.73 \%$

Test for overall effect: $\mathrm{Z}=3(\mathrm{P}=0)$

1.4.5 Change in tPCO2 during maximal exercise $(\mathrm{mm} \mathrm{Hg})$

$\begin{array}{lllll}\text { Marcus } 1992 & 22 & 10(4.7) & 22 & 6(4.7)\end{array}$

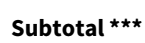

$22 \quad 22$

$6(4.7)$

Heterogeneity: Not applicable

Test for overall effect: $\mathrm{Z}=2.83(\mathrm{P}=0)$

1.4.6 SaO2 during maximal exercise (\%)

$\begin{array}{llrlr}\text { Falk } 2006 & 14 & 90.4(4.2) & 14 & 88.3(5.2) \\ \text { Nixon } 1990 & 23 & 97(1) & 23 & 95(2) \\ \text { Shah } 1997 & 17 & 97(4.1) & 17 & 95(4.1) \\ \text { Subtotal } \star \star \star & \mathbf{5 4} & & \mathbf{5 4} & \end{array}$

Heterogeneity: $\operatorname{Tau}^{2}=0 ; \mathrm{Chi}^{2}=0, \mathrm{df}=2(\mathrm{P}=1) ; \mathrm{I}^{2}=0 \%$

(4)

(4)

3)

(1)

(1)

Fixed, $95 \% \mathrm{Cl} \quad$ Fixed, $95 \% \mathrm{Cl}$

Test for overall effect: $Z=4.67(P<0.0001)$

Test for subgroup differences: $\mathrm{Chi}^{2}=11.3, \mathrm{df}=1(\mathrm{P}=0.05), \mathrm{I}^{2}=55.74 \%$

Favours room air 
Analysis 1.5. Comparison 1 Oxygen therapy versus control, Outcome 5 Change in gas exchange during sleep.

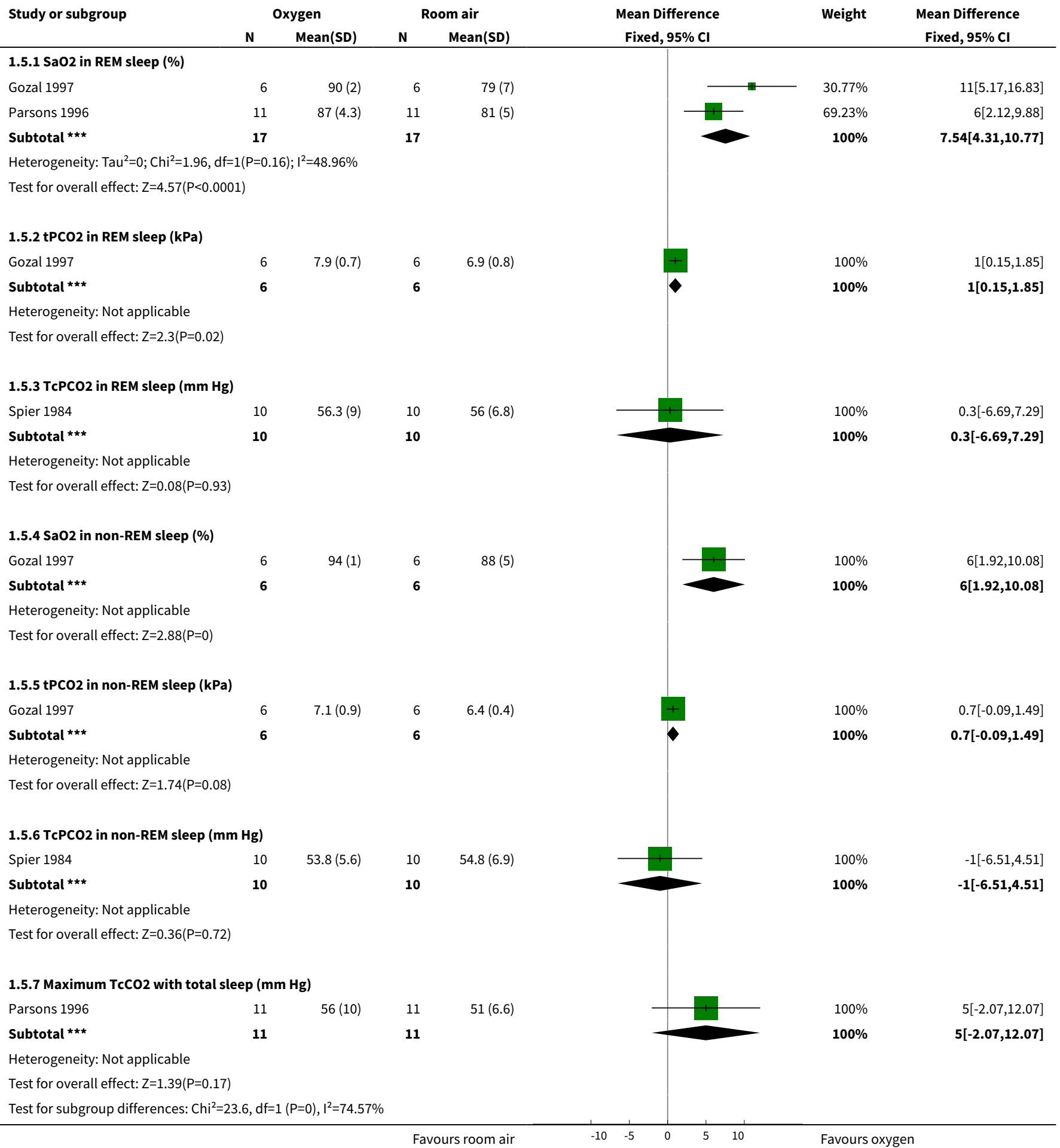

Oxygen therapy for cystic fibrosis (Review) 
Analysis 1.6. Comparison 1 Oxygen therapy versus control, Outcome 6 Change in $\mathrm{PaO2}$.

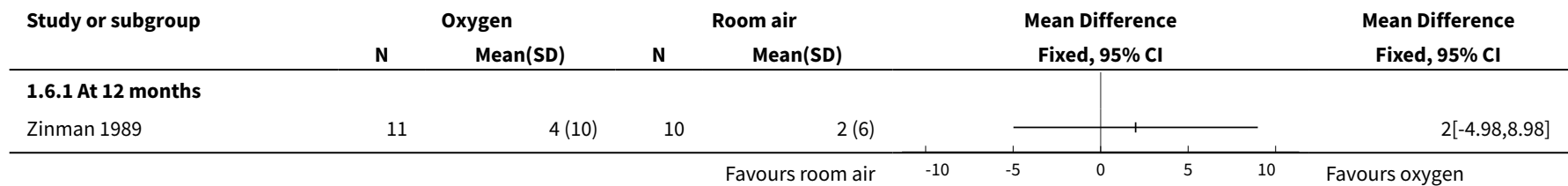

Analysis 1.7. Comparison 1 Oxygen therapy versus control, Outcome 7 Change in $\mathrm{PaCO}$.

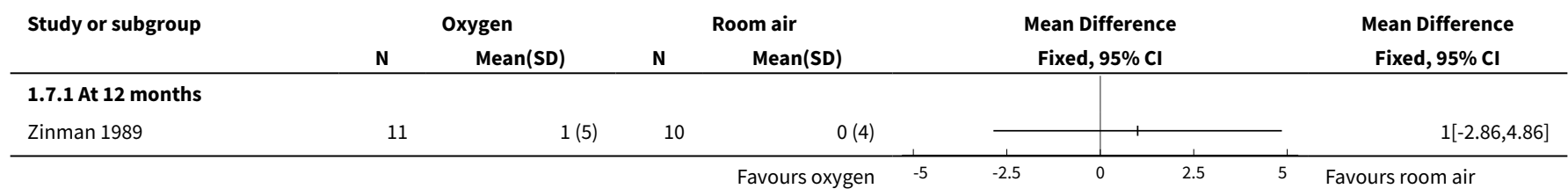

Analysis 1.8. Comparison 1 Oxygen therapy versus control, Outcome 8 Quality of life: regular attendance at school or work.

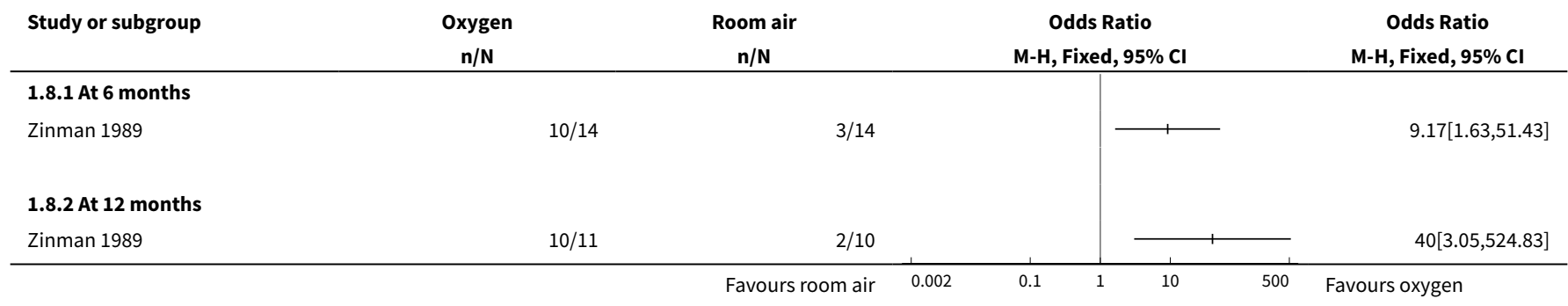

Analysis 1.9. Comparison 1 Oxygen therapy versus control, Outcome 9 Sleep parameters.

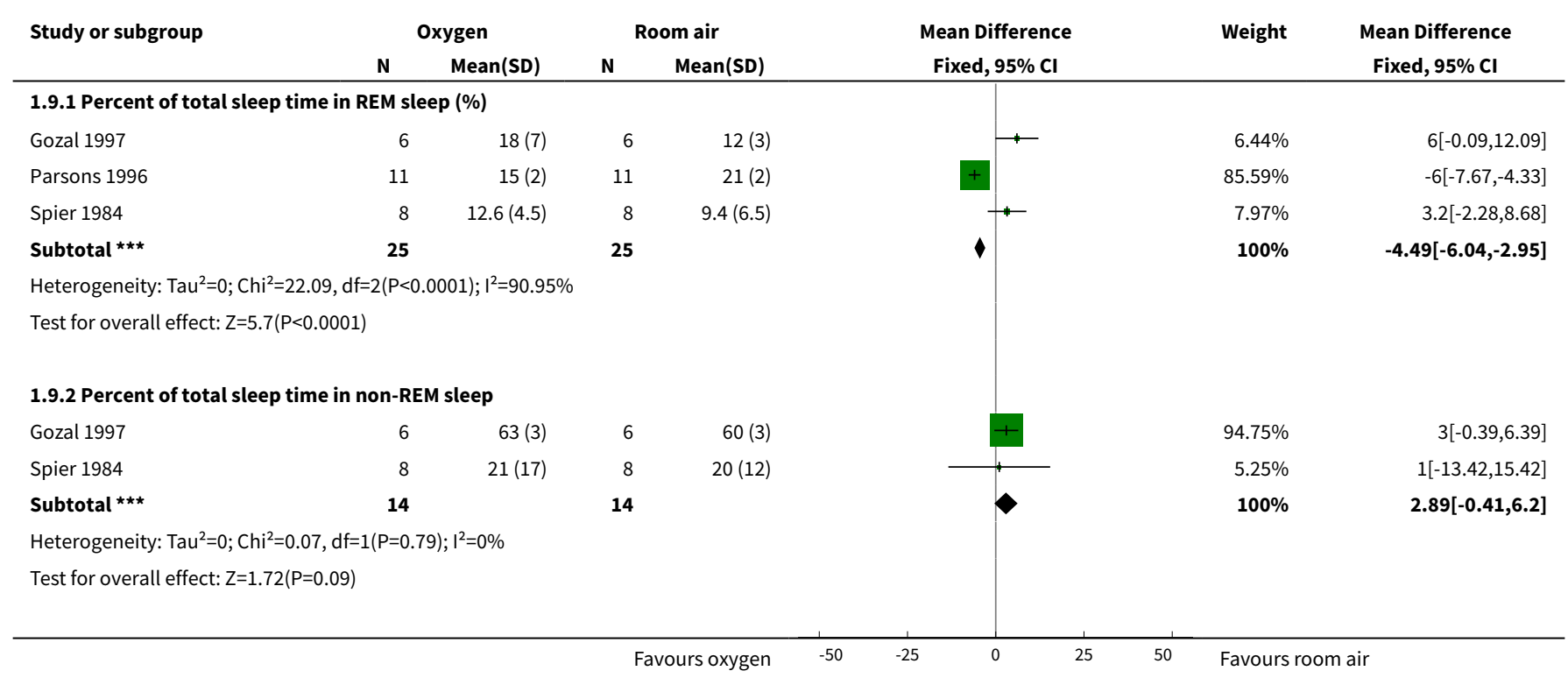




\begin{tabular}{|c|c|c|c|c|c|c|c|c|}
\hline \multirow[t]{2}{*}{ Study or subgroup } & \multicolumn{2}{|c|}{ Oxygen } & \multicolumn{2}{|c|}{ Room air } & \multirow{2}{*}{\multicolumn{2}{|c|}{$\begin{array}{c}\text { Mean Difference } \\
\text { Fixed, } 95 \% \mathrm{Cl}\end{array}$}} & \multirow[t]{2}{*}{ Weight } & \multirow{2}{*}{$\begin{array}{c}\text { Mean Difference } \\
\text { Fixed, } 95 \% \mathrm{Cl}\end{array}$} \\
\hline & $\mathbf{N}$ & $\operatorname{Mean}(S D)$ & $\mathbf{N}$ & $\operatorname{Mean}(S D)$ & & & & \\
\hline \multicolumn{9}{|c|}{ 1.9.3 Sleep latency (minutes) } \\
\hline Gozal 1997 & 6 & $18(2)$ & 6 & $24(6)$ & & & $100 \%$ & $-6[-11.06,-0.94]$ \\
\hline 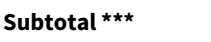 & 6 & & 6 & & & & $100 \%$ & $-6[-11.06,-0.94]$ \\
\hline \multicolumn{9}{|c|}{ Heterogeneity: Not applicable } \\
\hline \multicolumn{9}{|c|}{ Test for overall effect: $Z=2.32(P=0.02)$} \\
\hline \multicolumn{9}{|c|}{ 1.9.4 Total sleep time (minutes) } \\
\hline Gozal 1997 & 6 & $386(30)$ & 6 & $378(49)$ & & + & $49.38 \%$ & $8[-37.97,53.97]$ \\
\hline Spier 1984 & 8 & $382(18)$ & 8 & $386(63)$ & & $T$ & $50.62 \%$ & $-4[-49.4,41.4]$ \\
\hline 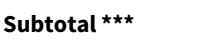 & 14 & & 14 & & & & $100 \%$ & $1.93[-30.38,34.23]$ \\
\hline \multicolumn{9}{|c|}{ Heterogeneity: $\mathrm{Tau}^{2}=0 ; \mathrm{Chi}^{2}=0.13, \mathrm{df}=1(\mathrm{P}=0.72) ; \mathrm{I}^{2}=0 \%$} \\
\hline \multicolumn{9}{|c|}{ Test for overall effect: $Z=0.12(P=0.91)$} \\
\hline \multicolumn{9}{|l|}{ 1.9.5 Arousal index } \\
\hline Gozal 1997 & 6 & $6(0.8)$ & 6 & $8.1(2.6)$ & & + & $100 \%$ & $-2.1[-4.28,0.08]$ \\
\hline 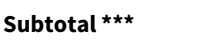 & 6 & & 6 & & & $\checkmark$ & $100 \%$ & $-2.1[-4.28,0.08]$ \\
\hline \multicolumn{9}{|c|}{ Heterogeneity: Not applicable } \\
\hline \multicolumn{9}{|c|}{ Test for overall effect: $\mathrm{Z}=1.89(\mathrm{P}=0.06)$} \\
\hline \multicolumn{9}{|c|}{ Test for subgroup differences: $\mathrm{Chi}^{2}=17.91, \mathrm{df}=1(\mathrm{P}=0), \mathrm{I}^{2}=77.66 \%$} \\
\hline & & & & rs oxygen & -50 & -25 & Favours $r$ & \\
\hline
\end{tabular}

Analysis 1.10. Comparison $10 x y g e n$ therapy versus control, Outcome 10 Exercise parameters after submaximal exercise.

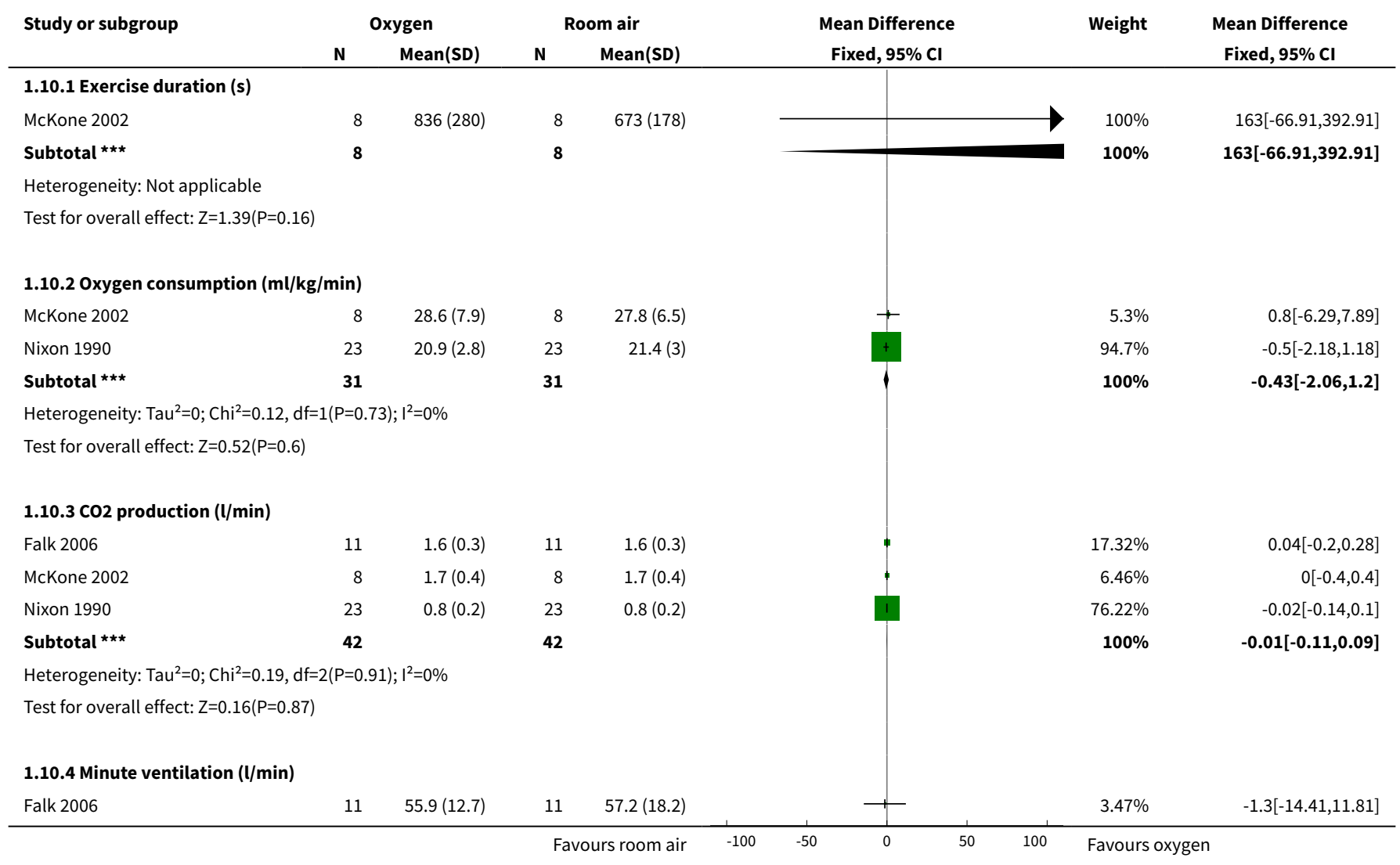




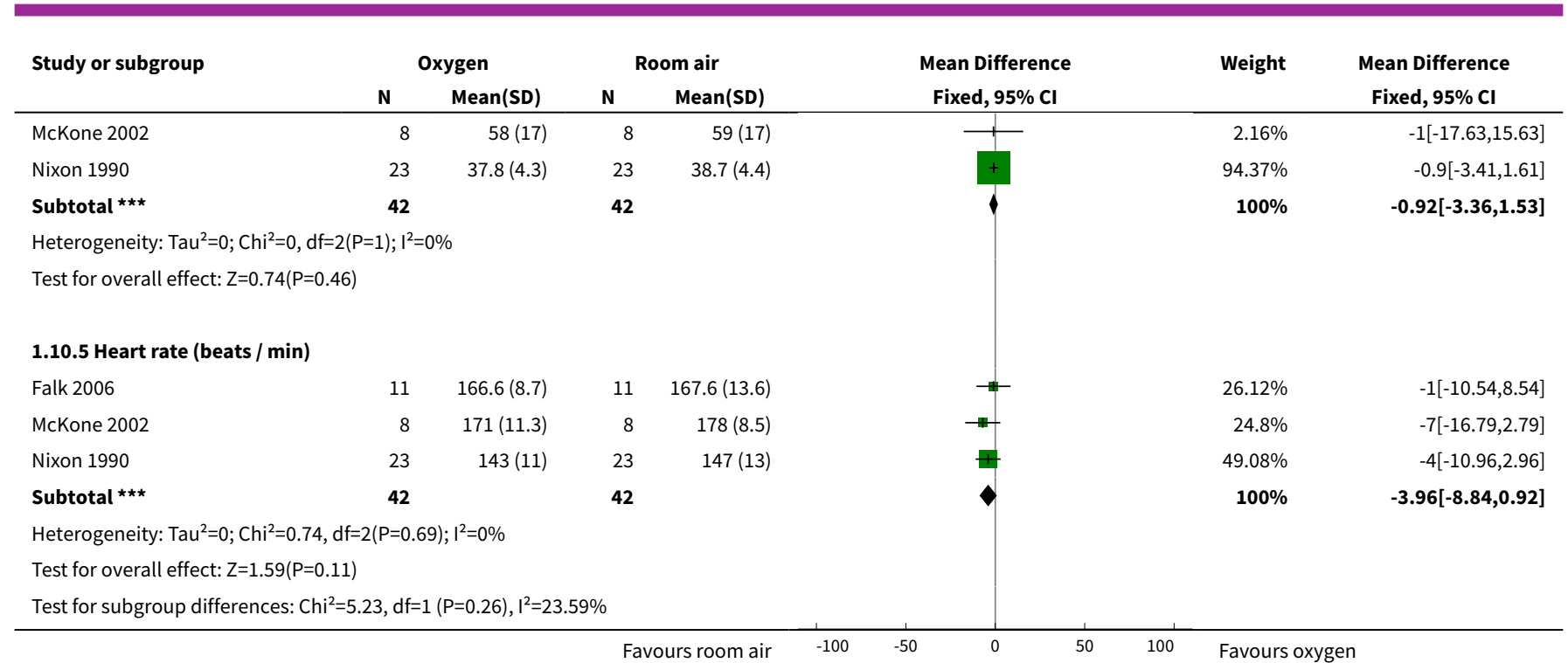

\section{Analysis 1.11. Comparison 1 Oxygen therapy versus control, Outcome 11 Exercise parameters during maximal exercise.}

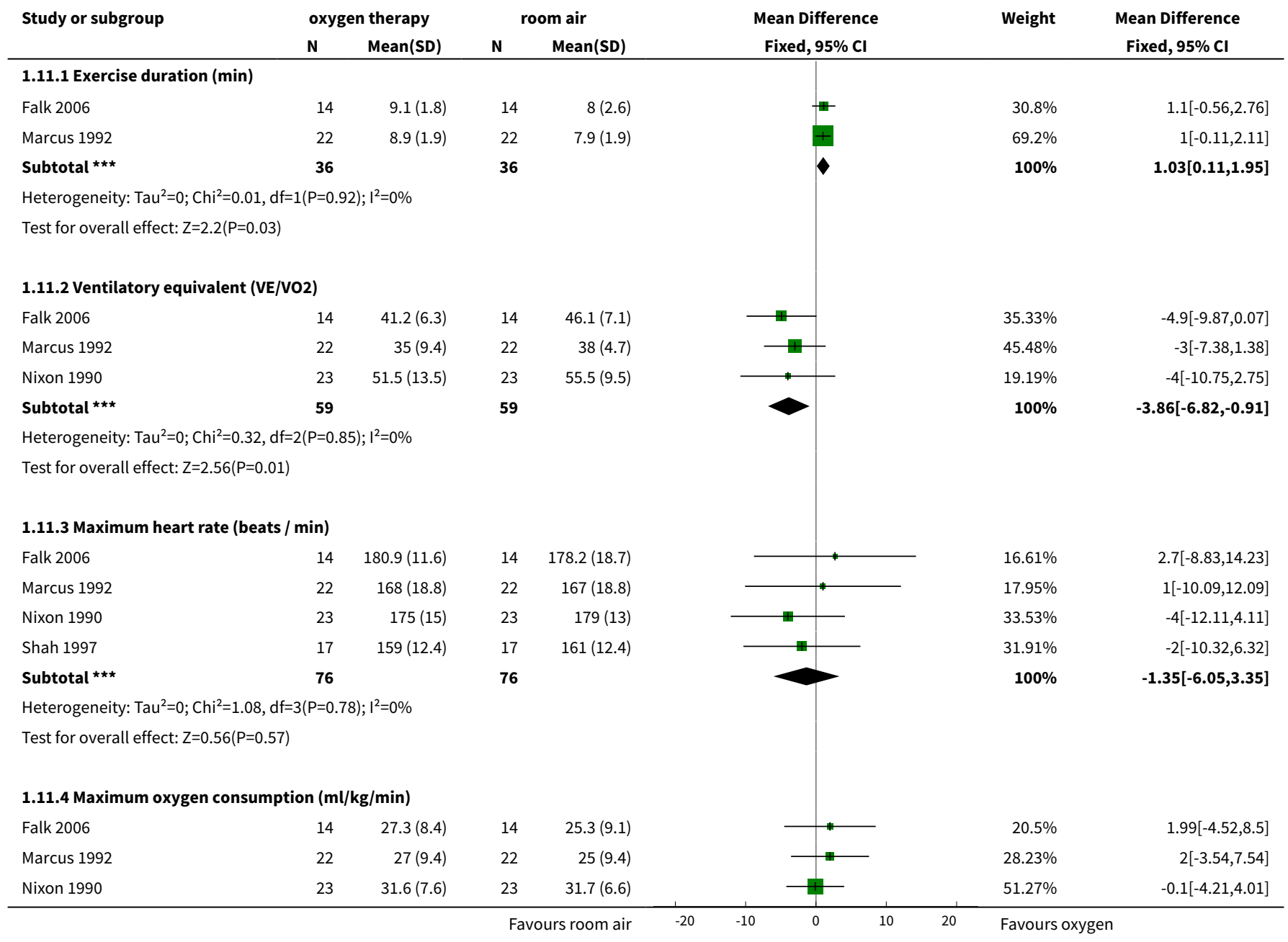




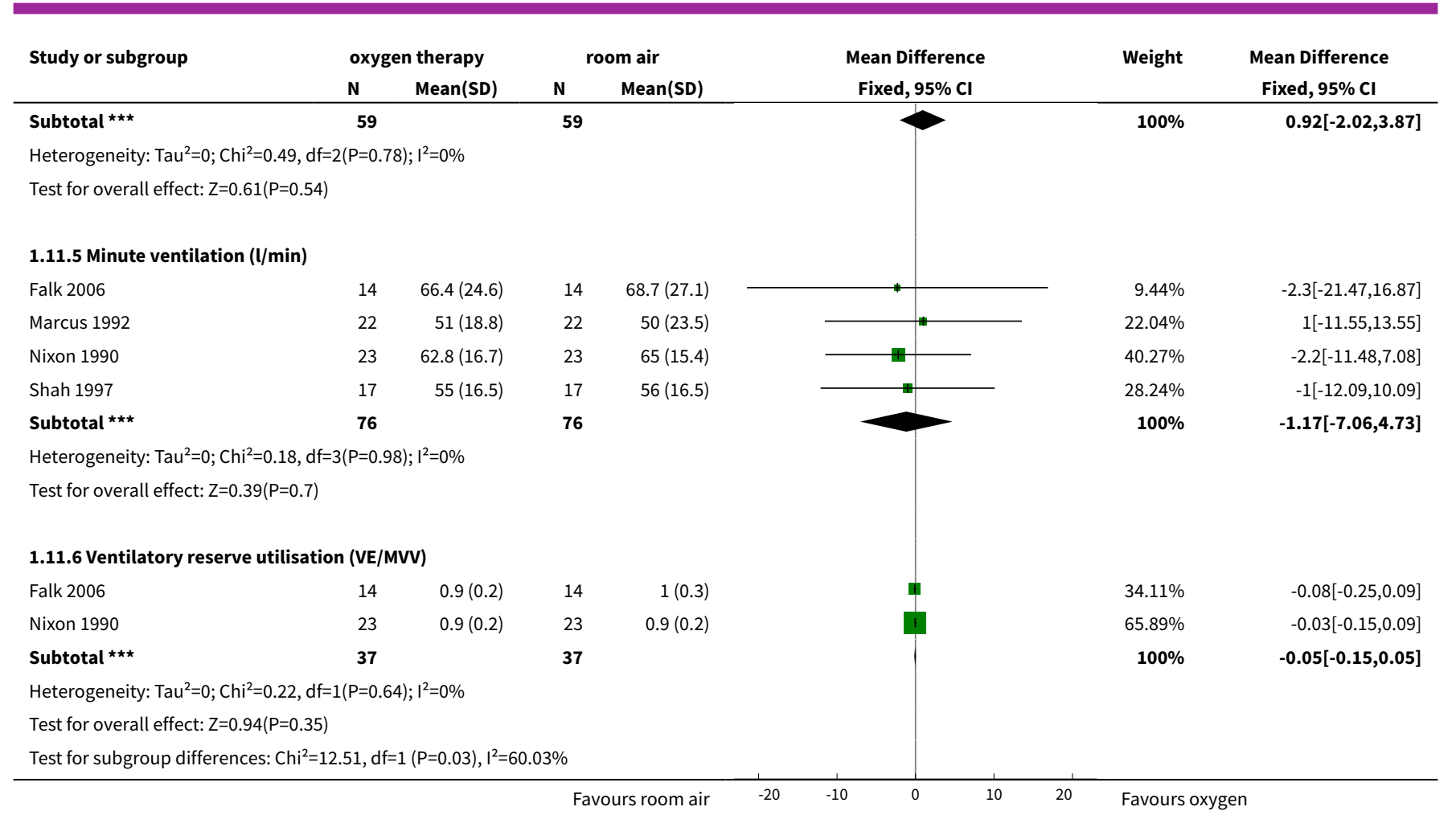

Analysis 1.12. Comparison 1 Oxygen therapy versus control, Outcome 12 Nutritional status: change in $\%$ ideal body weight for height.

\begin{tabular}{|c|c|c|c|c|c|c|}
\hline \multirow[t]{2}{*}{ Study or subgroup } & \multicolumn{2}{|c|}{ Oxygen } & \multicolumn{2}{|c|}{ Room air } & \multirow{2}{*}{$\begin{array}{c}\text { Mean Difference } \\
\text { Fixed, } 95 \% \mathrm{Cl}\end{array}$} & \multirow{2}{*}{$\begin{array}{c}\text { Mean Difference } \\
\text { Fixed, } 95 \% \mathrm{Cl}\end{array}$} \\
\hline & $\mathbf{N}$ & Mean(SD) & $\mathbf{N}$ & $\operatorname{Mean}(S D)$ & & \\
\hline \multicolumn{7}{|l|}{ 1.12.1 At 6 months } \\
\hline Zinman 1989 & 14 & $-1(4)$ & 14 & $1(4)$ & - & $-2[-4.96,0.96]$ \\
\hline \multicolumn{7}{|l|}{ 1.12.2 At 12 months } \\
\hline \multirow[t]{2}{*}{ Zinman 1989} & 11 & $0(5)$ & 10 & $1(5)$ & - & $-1[-5.28,3.28]$ \\
\hline & & & & urs room air & -2.5 & Favours oxygen \\
\hline
\end{tabular}

Analysis 1.13. Comparison 1 Oxygen therapy versus control, Outcome 13 Changes in right heart function.

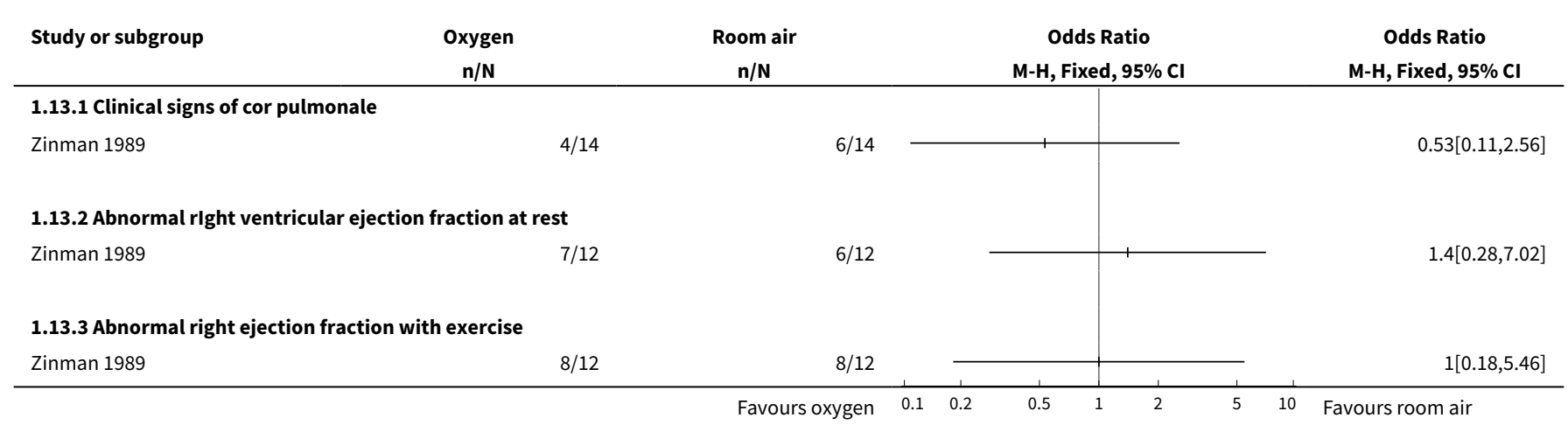




\section{ADDITIONAL TABLES}

Table 1. Abbreviations

\begin{tabular}{|c|c|}
\hline Abbreviations & Definition \\
\hline BiPAP & bileval positive airway pressure \\
\hline BMI & body mass index \\
\hline $\mathrm{CO} 2$ & carbon dioxide \\
\hline COPD & chronic obstructive pulmonary disease \\
\hline CPAP & continuous positive airway pressure \\
\hline ETCO2 & end tidal carbon dioxide tension \\
\hline FEV1 & forced expiratory volume in one second \\
\hline $\mathrm{FiO} 2$ & fraction of inspired oxygen, or percent of oxygen in the inspired gas \\
\hline FVC & forced vital capacity \\
\hline $\mathrm{kPa}$ & kilopascal, a unit of air pressure \\
\hline LVEF & left ventricular ejection fraction \\
\hline $\mathrm{mm} \mathrm{Hg}$ & millimeter of mercury, a unit of air pressure \\
\hline MVV & maximal voluntary ventilation \\
\hline NIPPV & non-invasive positive pressure ventilation \\
\hline NREM & non-rapid eye movement \\
\hline $\mathrm{PaCO} 2$ & arterial carbon dioxide tension \\
\hline $\mathrm{PaO} 2$ & partial pressure of oxygen in the blood \\
\hline PCO2 & partial pressure of carbon dioxide in the blood \\
\hline PETCO2 & maximum partial pressure of carbon dioxide exhaled during a tidal breath, just prior to inspiration \\
\hline REM & rapid eye movement \\
\hline RVEF & right ventricular ejection fraction \\
\hline $\mathrm{SaO} 2$ & saturation of haemoglobin with oxygen \\
\hline $\mathrm{SpO} 2$ & pulse oximetry \\
\hline $\mathrm{TcCO} 2$ & transcutaneous carbon dioxide \\
\hline $\mathrm{tPCO} 2$ & transcutaneous partial pressure of carbon dioxide in the blood \\
\hline
\end{tabular}


Table 1. Abbreviations (Continued)
VCO2
carbon dioxide production

VE mean total ventilation

VO2 oxygen consumption

WHAT'S NEW

\begin{tabular}{lll}
\hline Date & Event & Description \\
\hline 12 August 2013 & Review declared as stable & $\begin{array}{l}\text { Although we are not able to draw any firm conclusions on the ef- } \\
\text { fects of long-term oxygen therapy on patients with cystic fibro- } \\
\text { sis, we do not expect any new research in this area to be under- } \\
\text { taken and therefore do not plan to actively update this review. } \\
\text { However, a search of the Cystic Fibrosis and Genetic Disorders } \\
\text { Review Group's Cystic Fibrosis Trials Register will still be run on a } \\
\text { two-yearly basis and if any new evidence is identified, we will up- } \\
\text { date the review at that time. }\end{array}$ \\
\end{tabular}

\section{H I S T O R Y}

Protocol first published: Issue 4, 2002

Review first published: Issue 4, 2005

\begin{tabular}{lll}
\hline Date & Event & Description \\
\hline 3 July 2013 & $\begin{array}{l}\text { New citation required but conclusions } \\
\text { have not changed }\end{array}$ & $\begin{array}{l}\text { No new references were included in this update of the review } \\
\text { and our conclusions remain the same. }\end{array}$ \\
\hline
\end{tabular}

3 July $2013 \quad$ New search has been performed

A search of the Cochrane Cystic Fibrosis \& Genetic Disorders Review Group's Cystic Fibrosis Trials Register did not identify any new references potentially eligible for inclusion in this review.

\begin{tabular}{lll}
\hline 17 October 2012 & Amended & Contact details updated. \\
\hline 17 January 2011 & New search has been performed & $\begin{array}{l}\text { A search of the Group's Cystic Fibrosis Trials Register identified } \\
\text { nine references to six studies. All of these were excluded (Elkins } \\
\end{array}$ \\
& $\begin{array}{l}\text { 2004; Fauroux 1999; Fauroux 2000; Placidi 2006; Riethmueller } \\
\text { 2006; Young 2008). } \\
\text { In line with current Cochrane Collaboration guidance, the risk of } \\
\text { bias tables for the studies already included in this review have } \\
\text { been updated. }\end{array}$ \\
\hline
\end{tabular}

$\begin{array}{ll}10 \text { November } 2008 & \begin{array}{l}\text { New citation required but conclusions } \\ \text { have not changed }\end{array}\end{array}$

10 November $2008 \quad$ New search has been performed
Dr Heather Elphick has taken on lead authorship of the review and $\mathrm{Dr}$ George Mallory is remaining as co-author on the review.

A search of the Group's register identified two new references. One was a reference to an already included study (McKone 2002); the other was a reference to a new study and has been included in the review (Falk 2006). 


\begin{tabular}{lll}
\hline Date & Event & Description \\
\hline & $\begin{array}{l}\text { One study previously listed as 'Awaiting assessment' has now } \\
\text { been included (Barker 1998). Four studies previously listed as } \\
\text { 'Awaiting assessment' have now been excluded (Fauroux 2001; } \\
\text { Fauroux 2004; Holland 2003; Stewart 2001). }\end{array}$ & $\begin{array}{l}\text { Converted to new review format. } \\
\text { Amended }\end{array}$ \\
& $\begin{array}{l}\text { There have also been some changes made to the review in light } \\
\text { of comments from the Group's medical statistician. }\end{array}$ & $\begin{array}{l}\text { Plain language summary has been updated in line with latest } \\
\text { guidance from The Cochrane Collaboration. }\end{array}$
\end{tabular}

\section{CONTRIBUTIONS OF AUTHORS}

The title for the protocol was conceived by George Mallory and the Cochrane Cystic Fibrosis and Genetic Disorders Group. Both David Vaughan and George Mallory designed and assisted in writing the protocol.

George Mallory and David Vaughan selected and assessed most of the studies and wrote the initial drafts. Jason Fullmer further assessed the studies, extracted data, created the figures and, with George Mallory, wrote the full review.

Heather Elphick has drafted the updated review and acts as guarantor of the review.

\section{DECLARATIONS OF INTEREST}

None known.

\section{DIFFERENCES BETWEEN PROTOCOLANDREVIEW}

No subgroups analyses were planned in the original protocol and review. Post hoc plans for subgroup analyses have been added.

\section{N DEX TERMS}

\section{Medical Subject Headings (MeSH)}

*Oxygen Inhalation Therapy [adverse effects]; Cystic Fibrosis [*complications] [mortality]; Exercise Tolerance; Hypercapnia [etiology]; Hypoxia [etiology] [mortality] [^therapy]; Quality of Life; Randomized Controlled Trials as Topic; Sleep

\section{MeSH check words}

Humans 